\title{
Multi-MW accelerator target material properties under proton irradiation at Brookhaven National Laboratory linear isotope producer
}

\author{
N. Simos, ${ }^{1,}{ }^{*}$ H. Ludewig, ${ }^{1}$ H. Kirk, ${ }^{1}$ E. Dooryhee, ${ }^{1}$ S. Ghose,${ }^{1}$ Z. Zhong, ${ }^{1}$ H. Zhong, ${ }^{1}$ \\ S. Makimura, ${ }^{2}$ K. Yoshimura, ${ }^{3}$ J. R. J. Bennett, ${ }^{4}$ G. Kotsinas, ${ }^{5}$ Z. Kotsina, ${ }^{6}$ and K. T. McDonald ${ }^{7}$ \\ ${ }^{1}$ Brookhaven National Laboratory, Upton, New York 11973, USA \\ ${ }^{2}$ Muon Science Section, Materials and Life Science Division, J-PARC center, Tokai, Ibaraki 319-1195, Japan \\ ${ }^{3}$ Research Institute for Interdisciplinary Science, Okayama University, 1-1-1 Tsushima-naka, \\ Kita-ku, Okayama, Okayama Prefecture 700-8530, Japan \\ ${ }^{4}$ Science and Technology Research Council, Rutherford Appleton Laboratory, Harwell Campus, \\ Didcot, OX11 OQX, United Kingdom \\ ${ }^{5}$ Administration of Secondary Education of Thesprotia $(\Delta \Delta E \Theta)$, 46100 Igoumenitsa, Greece \\ ${ }^{6}$ National Centre of Scientific Research "Demokritos", 15341 Agia Paraskevi, Athens, Greece \\ ${ }^{7}$ Joseph Henry Laboratories, Princeton University, Princeton, New Jersey 08544, USA
}

(Received 17 December 2017; published 29 May 2018)

\begin{abstract}
The effects of proton beams irradiating materials considered for targets in high-power accelerator experiments have been studied using the Brookhaven National Laboratory's (BNL) $200 \mathrm{MeV}$ proton linac. A wide array of materials and alloys covering a wide range of the atomic number $(\mathrm{Z})$ are being scoped by the high-power accelerator community prompting the BNL studies to focus on materials representing each distinct range, i.e. low-Z, mid- $Z$ and high-Z. The low range includes materials such as beryllium and graphite, the midrange alloys such as Ti-6Al-4V, gum metal and super-Invar and finally the high-Z range pure tungsten and tantalum. Of interest in assessing proton irradiation effects are (a) changes in physiomechanical properties which are important in maintaining high-power target functionality, (b) identification of possible limits of proton flux or fluence above which certain materials cease to maintain integrity, (c) the role of material operating temperature in inducing or maintaining radiation damage reversal, and (d) phase stability and microstructural changes. The paper presents excerpt results deduced from macroscopic and microscopic post-irradiation evaluation (PIE) following several irradiation campaigns conducted at the BNL $200 \mathrm{MeV}$ linac and specifically at the isotope producer beam-line/target station. The microscopic PIE relied on high energy x-ray diffraction at the BNL NSLS X17B1 and NSLS II XPD beam lines. The studies reveal the dramatic effects of irradiation on phase stability in several of the materials, changes in physical properties and ductility loss as well as thermally induced radiation damage reversal in graphite and alloys such as super-Invar.
\end{abstract}

DOI: 10.1103/PhysRevAccelBeams.21.053001

\section{INTRODUCTION}

High-performance targets under consideration to intercept multi-MW proton beams of a number of new particle accelerator initiatives depend almost entirely on the ability of the selected materials to withstand both the induced thermomechanical shock and simultaneously resist accumulated dose-induced damage. The latter manifests itself as radiation-induced change in the physiomechanical properties. The increased demand imposed on the targets of

\footnotetext{
*simos@bnl.gov
}

Published by the American Physical Society under the terms of the Creative Commons Attribution 4.0 International license. Further distribution of this work must maintain attribution to the author(s) and the published article's title, journal citation, and DOI. high-power accelerators, which amounts to an order of magnitude over the experience from accelerator experiments to date, has led to an extensive search and experimentation with several new alloys and composites. In addition, this search included renewed focus and interest on materials such as graphite which has been used extensively in both particle accelerators as target material and in nuclear reactors as a moderator. Driving the renewed interest in graphite is the variety of its lattice structure which may have a significant influence on its ability to operate safely at the increased demand levels of beam-induced shock and irradiation flux.

A wide array of materials and alloys spanning a wide atomic number $(\mathrm{Z})$ range, with choices for target materials made based on the desired secondary particle spectra (i.e. pions and kaons from proton interaction with the specific $\mathrm{Z}$ material) are being scoped by the high-power accelerator community prompting the BNL studies to focus on materials 
representing each distinct range, i.e. low-Z, mid-Z and high-Z. The low range includes materials such as beryllium (Be), AlBeMet and graphite, the midrange alloys such as Ti$6 \mathrm{Al}-4 \mathrm{~V}$, gum metal and super-Invar, and finally the high- $\mathrm{Z}$ range includes pure tungsten and tantalum. Of interest in assessing proton irradiation effects are (a) changes in physiomechanical properties which are important in maintaining high-power target functionality, (b) identification of possible limits of proton flux or fluence above which certain materials cease to maintain their integrity, (c) the role of material operating temperature in inducing or maintaining radiation damage reversal, and (d) phase stability and microstructural changes.

Specifically, beryllium in various grades has been studied [1-4] under the effects of neutrons for use in nuclear fission or fusion reactors and proton effects [5-8] on beryllium and AlBeMet (a material metal matrix made of $62 \%$ beryllium and $38 \%$ aluminum by weight) for accelerator applications (targets and beam windows). Various grades of graphite have been explored over the decades for use as a nuclear reactor moderator material [9-14] and target in multi-MW proton accelerators $[15,16]$. Proton irradiation studies on graphite and carbon composites $[15,16]$ revealed a crucial fluence threshold $\left(\sim 5 \times 10^{20} \mathrm{p} / \mathrm{cm}^{2}\right.$ at low irradiation temperature $80^{\circ} \mathrm{C}-200^{\circ} \mathrm{C}$ ) that could affect the ability of the graphite to maintain its structural integrity. In addition, proton-induced damage has shown similarities with fast neutron-induced damage in terms of microscopic and macroscopic properties.

Several materials known as superalloys in the mid-Z range have been considered as pion yielding targets for the desired pion spectrum or as parts of the target critical infrastructure in high power accelerator initiatives such as the Neutrino Factory, the T2 K experiment, etc. These include Inconel-718, super-Invar, the gum multifunctional alloys and the titanium alloy Ti-6Al-4V. The attractiveness of these superalloys is derived from their high strength and for some, such as the super-Invar and gum alloys, from their low coefficient of thermal expansion (CTE) over an operating temperature window. Limited experience data under irradiation exists for these superalloys except for Ti$6 \mathrm{Al}-4 \mathrm{~V}$. The low CTE is of interest to the particle accelerator community in that it minimizes thermal stresses upon interaction with intense proton beams. Limited irradiationinduced effects are available for this alloy [14-18]. Prompted by their superb properties [superelasticity, superplasticity, low elastic modulus and high strength as well as its Invar-like characteristics (low CTE) over an extended temperature regime as compared to Invar] interest in the multifunctional alloys, known as gum metals [19,20], has increased $[16,21,22]$. Irradiation effects on the gum family of metals have only been discussed in [16]. Interest in titanium alloys exhibiting an attractive combination of thermophysical, mechanical and radioactive decay properties and identified as possible structural materials for different components in fusion reactors has led to studies
[22] of tensile and fracture toughness properties of unirradiated and neutron irradiated titanium $(\alpha+\beta)$ Ti6Al4 V and Ti5Al2.5Sn $(\alpha)$ alloys. The mechanical behavior of unirradiated Ti6Al4 V alloy was characterized [23] using uniaxial tension and compression as well as simple shear and plane strain tests in three orthogonal material directions revealing tension/compression asymmetry, anisotropic yielding and anisotropic strain hardening, behavior that is crucial in its intended applications. Proton irradiation of pure $\mathrm{Ti}$ and Ti6Al4V was conducted in [24] where postirradiation microstructural characterization was performed based on x-ray diffraction. Observed in [24] is that at high dose $\left(\sim 5 \times 10^{21} \mathrm{p} / \mathrm{m}^{2}\right)$ the diffraction peaks of Ti6Al4 V became highly asymmetric and attributed to the segregation of the alloying elements.

High- $\mathrm{Z}$ refractory metals such as $\mathrm{W}$ and $\mathrm{Ta}$ and their alloys, motivated by the many years of experience of the ISIS target at Rutherford-Appleton Laboratory (RAL), have been under consideration for a solid target option of the Neutrino Factory [25]. Edge cooled targets of randomly packed spheres, either iridium or tungsten, were considered in [26] for an accelerator driven pulsed neutron source. Radiation damage problems in high power spallation neutron sources, including tantalum and tungsten materials, were collected and discussed in [27]. Thermal shock measurements and modeling of tungsten wires subjected to repeated thermal stresses to assess fatigue lifetime at high temperatures while simulating a highpower solid target for the neutrino factory initiative were conducted in [28].

Presented in the subsequent sections are excerpt irradiation damage results on selected materials from the three (3) $\mathrm{Z}$ ranges. Results are deduced from macroscopic and microscopic post-irradiation evaluation (PIE) which followed a number of irradiation campaigns conducted at the BNL $200 \mathrm{MeV}$ linac and specifically the isotope producer beam-line/target station. The microscopic PIE relied on high energy $\mathrm{x}$-ray diffraction at (a) the $200 \mathrm{keV}$ polychromatic $\mathrm{x}$ rays at NSLS X17B1 beam line and (b) the $67 \mathrm{keV}$ monochromatic $x$ rays at the NSLS II XPD beam line. The studies revealed the dramatic effects of irradiation on phase stability in several of the materials, changes in physical properties and ductility loss as well as thermally induced radiation damage reversal in graphite and alloys such as super-Invar. For the refractory metal tungsten, correlation of macroscopic and microstructural data revealed that radiationinduced phase changes may be responsible for the dramatically brittle behavior following irradiation.

\section{EXPERIMENTAL}

\section{A. Proton irradiation experiments}

The Brookhaven Linac Isotope Producer (BLIP) beamline/endstation at the BNL collider-accelerator complex was used to perform the proton irradiation phase of the 
experimental effort. The BLIP beam-line/target station receives protons at energies up to $200 \mathrm{MeV}$ while operating at $3.75 \mathrm{~Hz}$. The average beam current has been steadily increasing from $\sim 95 \mu \mathrm{A}$ during the 2004 irradiation campaign to $165 \mu \mathrm{A}$ during the 2016-2017 run. The proton beam profile is Gaussian and since the 2015-2016 run beam raster capabilities have been introduced. The primary purpose of the BLIP beam-line/endstation is the production of medical isotopes by spallation of $118 \mathrm{MeV}$ protons by $\mathrm{RbCl}$ and $\mathrm{Ga}$ targets. To enable irradiation studies on accelerator materials (as reported herein) without impacting the medical isotope production higher energies of the linac are used (i.e. 161, 181 or $200 \mathrm{MeV}$ ) with the research target array placed upstream of the isotope targets and designed to consume the beam energy down to $118 \mathrm{MeV}$. Transport codes such as FLUKA $[29,30]$ are extensively used in the design of the irradiation experiments to ensure the proper beam energy degradation, beam profile, energy deposition, activation and radiation damage. FLUKA-based energy deposition throughout the research target array is used to estimate irradiation temperatures as well as thermomechanical stresses using the capabilities of numerical code LS-DYNA [31]. No in situ temperature monitoring is possible at the BLIP beam-line configuration due to the hermetically sealed target envelope and therefore the irradiation studies rely on benchmarked numerical models [32] for the temperature profile in the array during irradiation. Special nickel foils are inserted into the target arrays which, following radiography, reveal the exact position of the beam relative to the normal plane of the array, the size as well as the shape of the irradiating proton beam. This information is coupled with the measured beam current to produce a very close estimate of the proton fluence at each location within the array.

Test specimens, such as the ones shown in Figs. 1(a) and 1(b) along with their assembly relative to the proton beam path [Fig. 1(c)], were used in the study. The "dog bone" type specimen [Fig. 1(a)] has been used for post-irradiation tensile and four-point-bending mechanical tests and the CTE specimen [Fig. 1(b)] is used for post-irradiation physical property measurements (thermal expansion, electrical resistivity, ultrasound-based material damage assessment, etc.). The arrangement of the "annealed" $\beta$-alloy (gum metal) shown with the special markings used to identify each sample during post-irradiation evaluation (PIE) is depicted in Fig. 1(c). The specimen layers, depending on the desired irradiation temperature, are either enclosed in special capsules under vacuum or inert gas atmospheres or are assembled in special cassettes that allow deionized water to flow in cooling channels that exist between the material layers and be in direct contact with the irradiated samples. Shown in Fig. 1(d) is a beam-induced thermal profile of a capsule containing a target array shown in Fig. 1(c) generated using finite element techniques [31].

\section{B. Materials of study}

Presented in this section is the list of materials selected for the irradiation experiments at BLIP along with a brief background and characterization that prompted their consideration for evaluation and potential use as high-power accelerator targets.

For the low- $\mathrm{Z}$ class, materials considered include the beryllium grade S200-F, the composite AlBeMet-162 (as a possible alternative to beryllium) and the two Toyo Tanso Co. IG-43 and IG-430 isotropic graphite grades. S200-F beryllium and AlBeMet were selected for possible use as low-Z pion production targets of beam windows. AlBeMet, a high-beryllium binary alloy with aluminum that is best described as a metal matrix composite rather than an alloy since the two metals remain as separate phases, was considered because it exhibits desirable physiomechanical properties. It consists of $62 \%$ by weight beryllium with the balance in 1100 series aluminum. The two isotropic
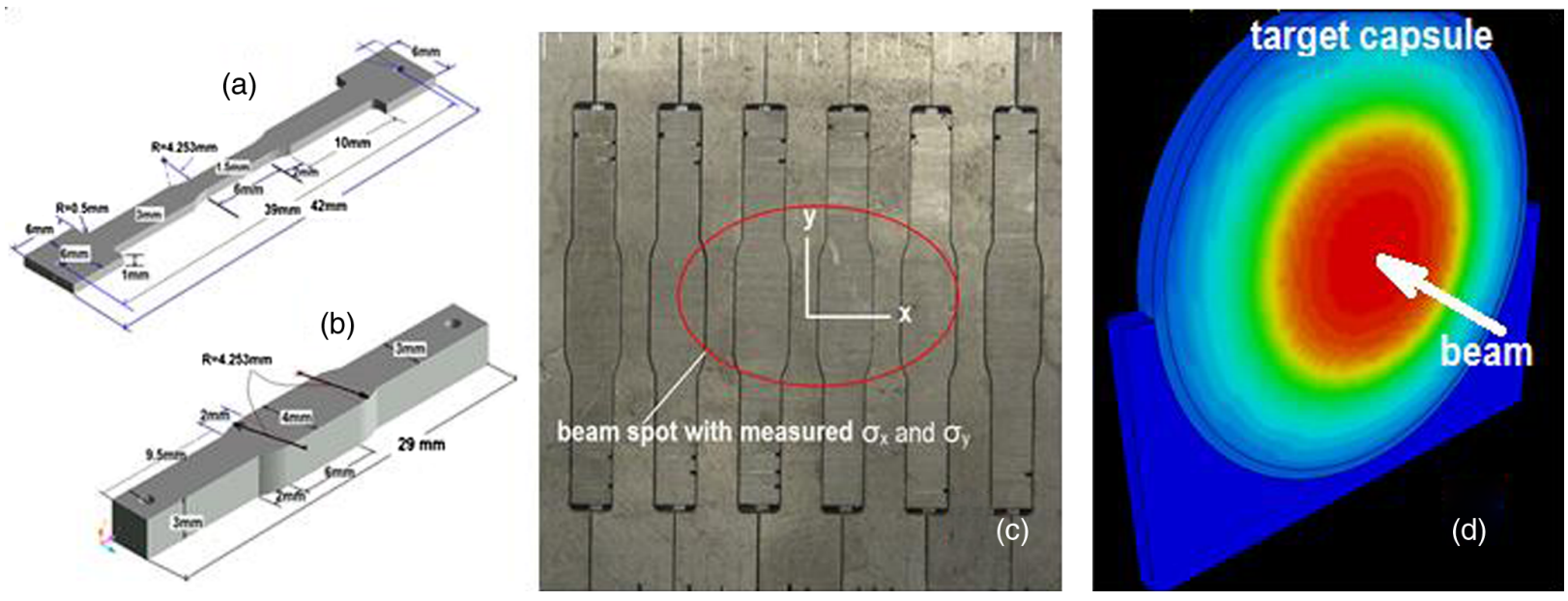

FIG. 1. (a) and (b) Geometry of test samples used in the irradiation studies, (c) sample array layout during irradiation, and (d) beam-induced thermal profile using finite element analysis techniques. 
graphite grades (IG-43 and IG-430) are materials of interest in target concepts (neutrino superbeam, J-PARC muon, etc.) as well as nuclear reactor materials.

Several alloys, also known as superalloys representing the mid-Z range, were selected explored as target materials in the neutrino factory initiative. These included Invar 32-5 (or super-Invar) the $(\alpha+\beta)$ Ti-6Al-4V alloy and the $\beta$-titanium alloy known as gum metals. Properties of interest in these superalloys (other than pion yield and spectra) are their mechanical strength and their dimensional and phase stability.

Super-Invar.-Invar, also defined as FeNi36, is a nickeliron alloy with extremely low expansion coefficient and was invented by physicist Guillaume in 1896 leading to the 1920 Nobel Prize in physics due to the impact the material had on the improvement of scientific instruments. Invar refers to the anomalously low coefficient of thermal expansion (CTE) of a binary, iron-nickel alloy i.e. Invar$36{ }^{\circledR}$ alloy (64 wt $\% \mathrm{Fe}$ and $36 \mathrm{wt} \% \mathrm{Ni}$ ). Addition of cobalt has resulted in what is known as super-Invar 32-5, a magnetic, austenitic, alloy consisting of iron, nickel and cobalt (64 wt $\% \mathrm{Fe}, 31 \mathrm{wt} \% \mathrm{Ni}$, and. $5 \mathrm{wt} \% \mathrm{Co}$ ) exhibiting almost a zero CTE at room temperature was selected to study proton irradiation effects. The extremely low CTE is the primary reason behind the selection and study of this alloy for potential use as an accelerator target.

Gum metal (Ti-21Nb-2Ta-3Zr-1.2O).- This $\beta$-type multifunctional alloy in both the "as-annealed" and $90 \%$ cold-worked states was selected for study to assess its potential use as a high-power accelerator target material. The multifunctional $\beta$-type titanium alloy (body-centered cubic) has been developed by Saito et al. [19]. Gum metal is a trademark of Toyota Central R\&D Labs, Inc., Aichi, Japan. This alloy is claimed to possess the following "super properties": ultralow elastic modulus, ultrahigh strength, ultrahigh elastic deformability, superductility, superelasticity at room temperature, invar and elinvar properties attributed according to [19] to unconventional localized lattice distortions (dislocation-free plastic deformation). Serious debate, however, exists $[21,33]$ as to the responsible mechanism behind the superplasticity (dislocation-free plastic deformation vs martensitic transformations). Their unusual mechanical behavior at room temperature, when deformed in tension gum metal exhibits high yield stress (up to $1 \mathrm{GPa}$ ) and outstanding elongation to failure [19].

Ti-6Al-4V.- This titanium alloy, owed to its attractive thermophysical and mechanical properties (high strength) and in addition radioactive decay properties, has been considered as a material for components in fusion reactors. The high strength, lower than steel CTE and phase stability that characterize this alloy have prompted its consideration as a candidate material in accelerator target systems and its inclusion in these proton-irradiation studies. Ti-6Al-4V alloy is a dual phase material. Titanium is an allotropic material, with a high temperature body-centered cubic (bcc) phase, known as the $\beta$ phase, and a low temperature hexagonal close-packed (hcp) phase, known as the $\alpha$ phase. In Ti-6Al-4V the alloying elements aluminum and vanadium are included as $\alpha$ - and $\beta$-phase stabilizers, respectively. This alloying results in a small volume fraction of the $\beta$-phase being retained at room temperature. Due to the low volume fraction $(5 \%-10 \%)$ of the $\beta$-phase typically present in Ti- $6 \mathrm{Al}-4 \mathrm{~V}$, it is generally assumed that the bcc $\beta$ phase plays a secondary role in the bulk mechanical behavior of Ti-6Al-4V. Limited research has been conducted on the irradiation effects on the physiomechanical properties and the stability of its phases.

Refractory metals $W$ and Ta (high-Z). - Tantalum and tungsten test specimens of the CTE and tensile types shown in Fig. 1 were selected for irradiation damage studies at BLIP. Tungsten and tantalum are materials of interest as targets in spallation sources such as ISIS (RAL, UK) and the European Spallation Source (ESS, Sweden) as well as for applications in fusion energy reactors such as ITER.

\section{Post-irradiation examination (PIE)}

The post-irradiation analysis of the proton-irradiated materials consisted of two parts, namely the macroscopic assessment (stress strain and CTE) and the microscopic evaluation based on x-ray diffraction techniques at the BNL synchrotron light sources NSLS and NSLS II. The macroscopic evaluation of irradiation damage on the tested materials for all the irradiation campaigns was conducted at the BNL hot cell laboratories that are within the Isotope Processing Facility. The macroscopic study consisted of (a) tensile stress strain and four-point bending tests as well as ductility loss using a Tenius-Olsen mechanical tester, (b) thermal stability analysis, annealing and changes in the coefficient of thermal expansion (CTE) using a high sensitivity LINSEIS dilatometer. In this paper, the macroscopic post-irradiation assessment focuses on stress-strain relationships, dimensional stability, CTE and annealing of selected classes of materials. Stress-strain relationships were deduced during with cross-head speed in the Tenius-Olsen tensile tester set at $1 \mathrm{~mm} /$ minute.

The microscopic analysis utilized $\mathrm{x}$-ray diffraction techniques with high-energy monochromatic and white $\mathrm{x}$-ray beams at the NSLS and the NSLS II synchrotrons of BNL. Energy dispersive $\mathrm{x}$-ray diffraction (EDXRD) techniques were used at the X17B1 beam line of NSLS using a $200 \mathrm{keV}$ white $\mathrm{X}$-ray beam with in situ four-point-bending stress. Monochromatic, $70 \mathrm{keV} x$ rays at the NSLS X17 A and the NSLS II XPD beam lines were utilized in a series of XRD-based post-irradiation studies. Excerpt results of the $\mathrm{X}$-ray based microscopic analyses are included to explain the macroscopic observations.

\section{ASSESSMENT OF IRRADIATION DAMAGE}

This section includes excerpt results of both macroscopically and microscopically obtained proton irradiation 

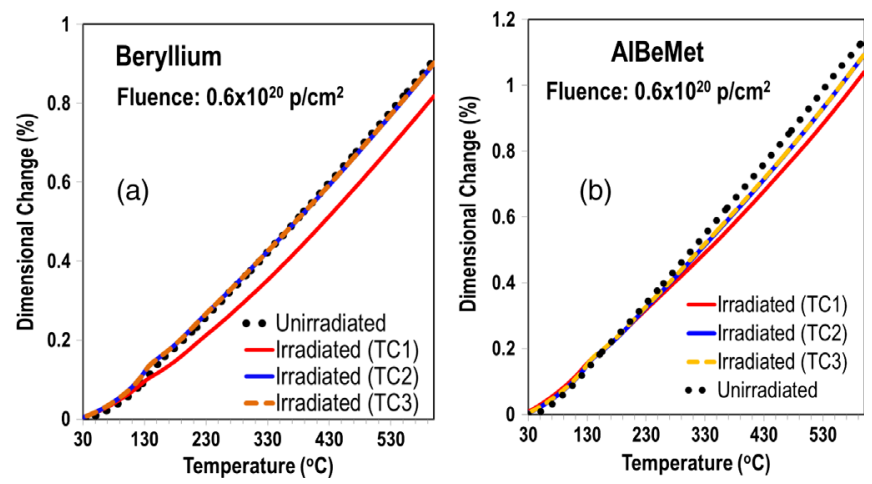

FIG. 2. Dimensional change reversal with post-irradiation thermal cycling in (a) beryllium and (b) AlBeMet.

effects on material properties. Specifically, representative materials of the low-Z, mid- $Z$ and high- $Z$ classes under consideration in next generation particle accelerators such as the muon collider/neutrino factory have been selected and discussed in separate subsections.

\section{A. Beryllium, AlBeMet and graphite damage studies}

S200-F beryllium and AlBeMet.-These two materials were studied for possible use as low-Z pion production targets or beam windows. Test samples similar to those shown in Figs. 1(a) and 1(b) were irradiated at BLIP to peak fluence of $\sim 1.2 \times 10^{20} \mathrm{p} / \mathrm{cm}^{2}$ and irradiation temperature varying based on the sample position $\left[\mathrm{T}_{\text {irr }} 80^{\circ} \mathrm{C}-200^{\circ} \mathrm{C}\right.$ per Fig. 1(c)]. The irradiation was conducted in deionized cooling water flowing past the sample surfaces in order to keep the temperature low. Shown in Fig. 2 are dimensional changes in the respective CTE samples for beryllium and AlBeMet exposed to the highest average fluence [average fluence computed over the CTE sample of Fig. 1(b)]. Post-irradiation annealing via several thermal cycles (i.e. TC1 refers in Fig. 2 to first thermal annealing cycle during post-irradiation evaluation) to $600^{\circ} \mathrm{C}$ reveals that beryllium reverses the damage almost entirely in contrast with
AlBeMet where the observed irreversibility of damage is attributed to the aluminum content. The CTE evolution as a function of the average fluence is depicted in Figs. 3(a) and 3(b) for beryllium and AlBeMet, respectively.

Tensile test results of beryllium and AlBeMet are shown in Fig. 4. The as-received materials exhibited no scattering in the tensile test data [5]. For this low proton dose $\left(\sim 1.2 \times 10^{20} \mathrm{p} / \mathrm{cm}^{2}\right)$ both materials maintain a significant portion of their original ductility. Worth noting on Fig. 4(b) is the stress-strain behavior of irradiated AlBeMet at the high end of the irradiation temperature range $\left(\sim 200^{\circ} \mathrm{C}\right)$ where it appears that it maintains $\sim 90 \%$ of its ductility. The difference observed in the elongation of the two materials is attributed to the fact that AlBeMet is a composite matrix rather than an alloy. This is confirmed using x-ray diffraction results deduced from studies conducted at X17B1 beam line utilizing $200 \mathrm{keV}$ polychromatic $\mathrm{x}$ rays and a slit size of $20 \mu \mathrm{m}$. The confirmatory results are depicted in Fig. 5 where the two phases (beryllium and aluminum) are distinct and remain so following irradiation.

Graphite.-Prompted by the need to identify low-Z targets for the neutrino factory, the BNL neutrino superbeam concept and other high-power accelerator initiatives, several graphite grades were irradiated and studied for both macroscopic (dimensional stability, CTE and damage annealing) and microstructural changes. Reported in this paper are proton effects on two isotropic graphite grades IG-43 and IG-430 (Toyo Tanso). Shown in Fig. 6(a) are post-irradiation thermal cycle annealing (to $300^{\circ} \mathrm{C}$ ) and the evolution of CTE [Fig. 6(b)] with temperature and proton fluence of IG-430 graphite. Figure 6(a) reveals that upon annealing even to $300^{\circ} \mathrm{C}$ most of the induced damage is reversed. Deduced from Fig. 6(b) is that the CTE appears to reach a maximum and begins to decline as proton fluence increases. The trend is somewhat similar for IG-43 whose CTE as a function of fluence is shown in Fig. 7 for two temperatures $\left(250{ }^{\circ} \mathrm{C}\right.$ and $\left.550{ }^{\circ} \mathrm{C}\right)$. While the fluence for IG-43 is much lower and did not reach the threshold for the turnaround, the CTE reaches a plateau. Similar behavior of graphite under neutron irradiation has been observed

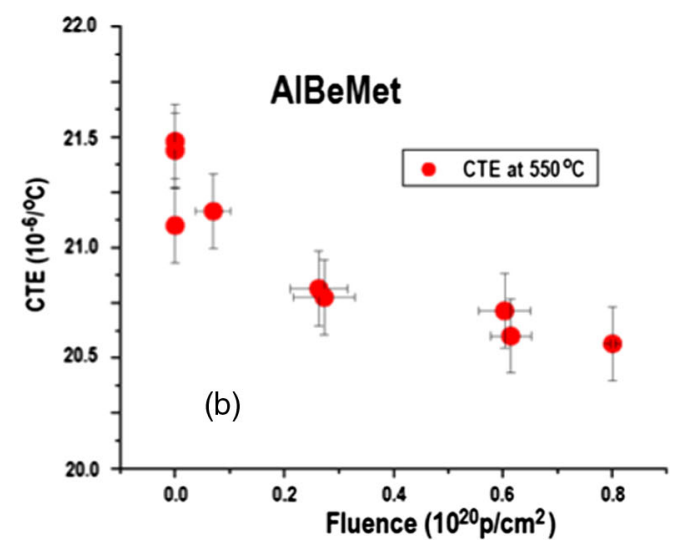

FIG. 3. Thermal expansion coefficients of irradiated beryllium (a) and AlBeMet (b) at $550{ }^{\circ} \mathrm{C}$. 

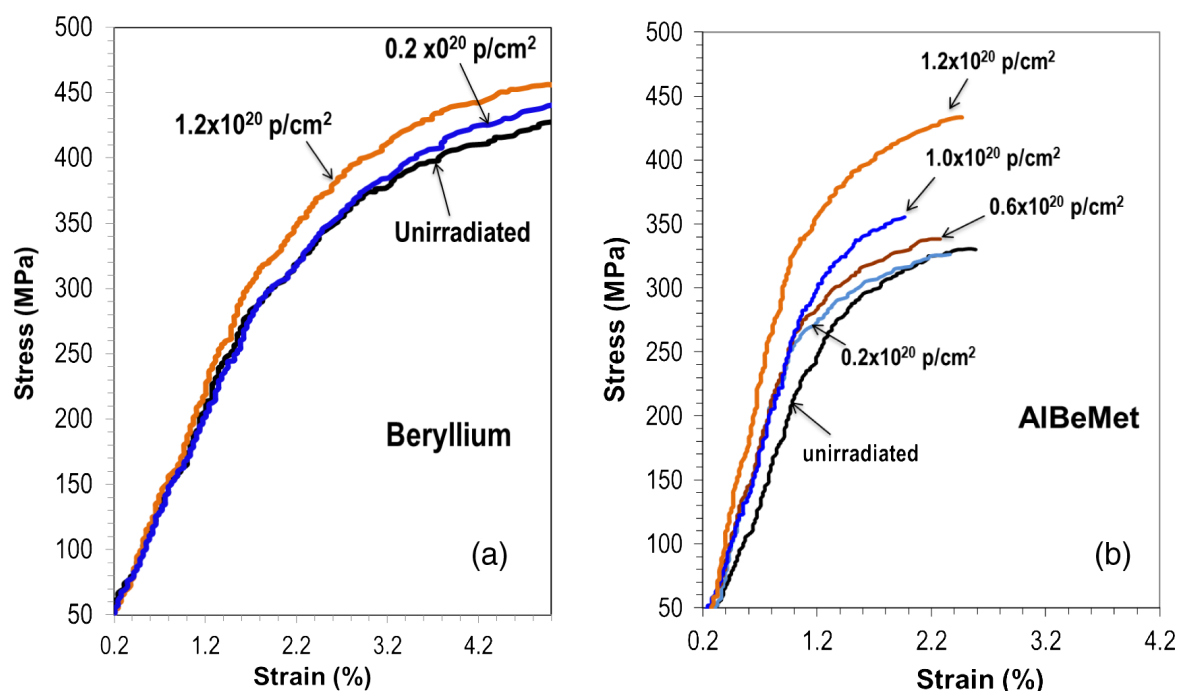

FIG. 4. Stress-strain relation of (a) beryllium and (b) AlBeMet.

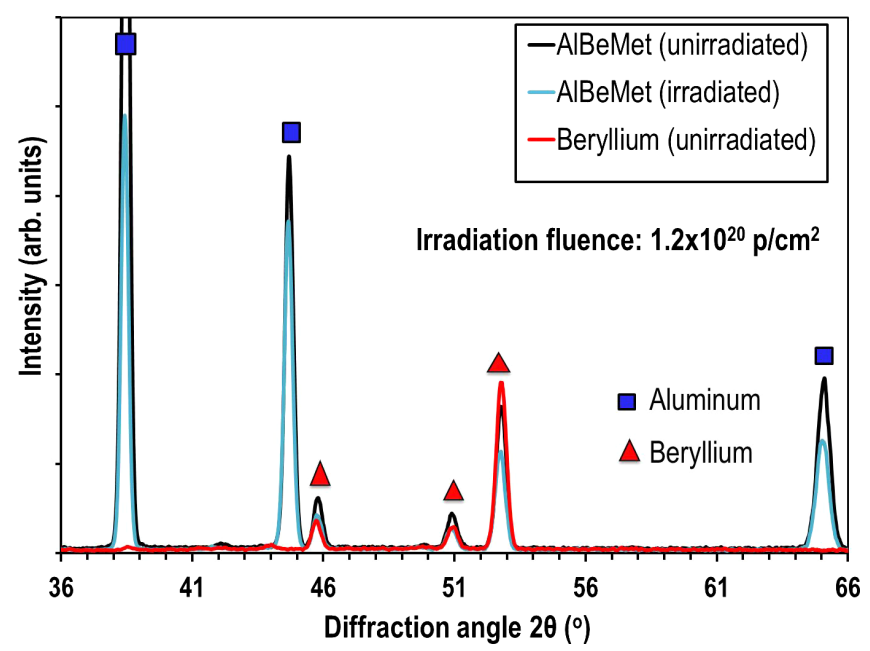

FIG. 5. X-ray diffraction map of beryllium and AlBeMet. in $[9,10,14]$. Post-irradiation tensile test results on IG-43 and IG-430 graphite grades are shown in Fig. 8. These highly isotropic graphite grades experience significant increases in their ultimate strength and elastic modulus as a result of proton irradiation, a finding that is in agreement with fast neutron irradiation results on graphite $[9,10]$. Results on the fractional change of Young's modulus [Fig. 8(c)] clearly show that at higher proton fluence the finer grained graphite IG-430 is showing a downward slope.

The impact of the fluence level on the degradation of graphite microstructure has been verified via an irradiation experiment of a novel target concept for the J-PARC Muon Facility. Specifically, a target concept where the transfer of heat from the central part made of IG-43 graphite and is irradiated by the beam is aided by a copper outer segment to take advantage for its high conductivity was envisioned [34]. Titanium was considered as the
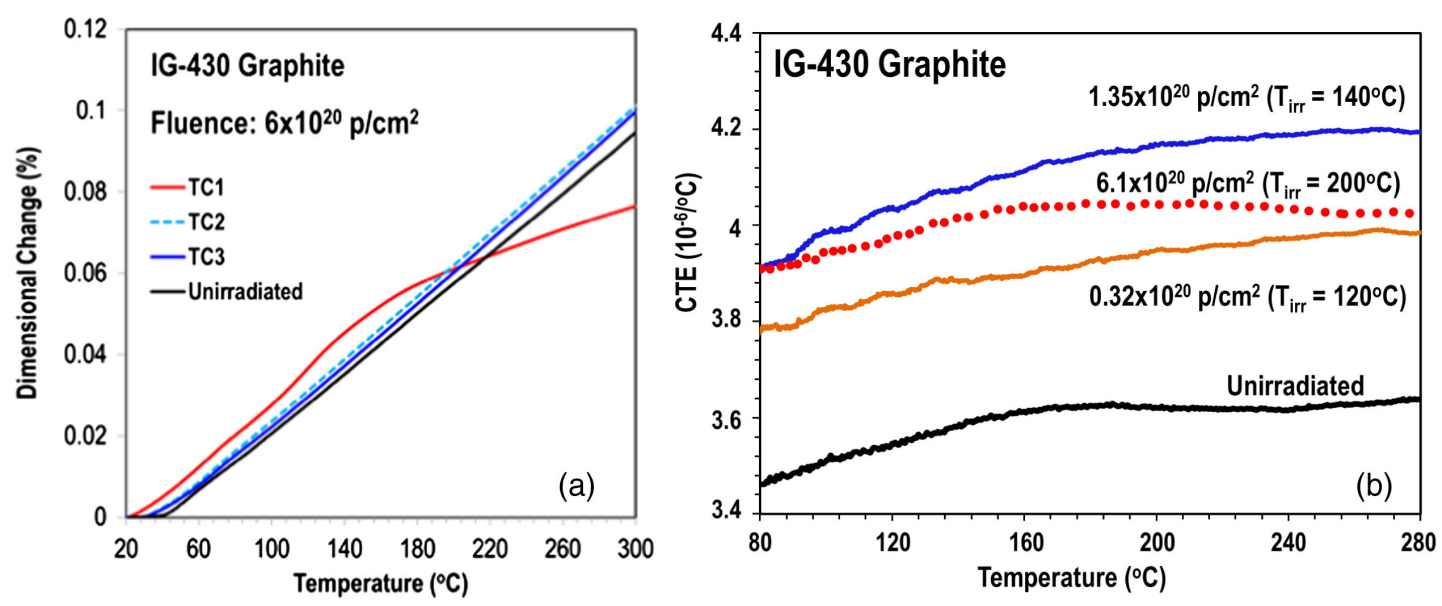

FIG. 6. (a) Post-irradiation thermal cycle annealing and (b) CTE as a function of fluence and temperature of IG-430 graphite. 

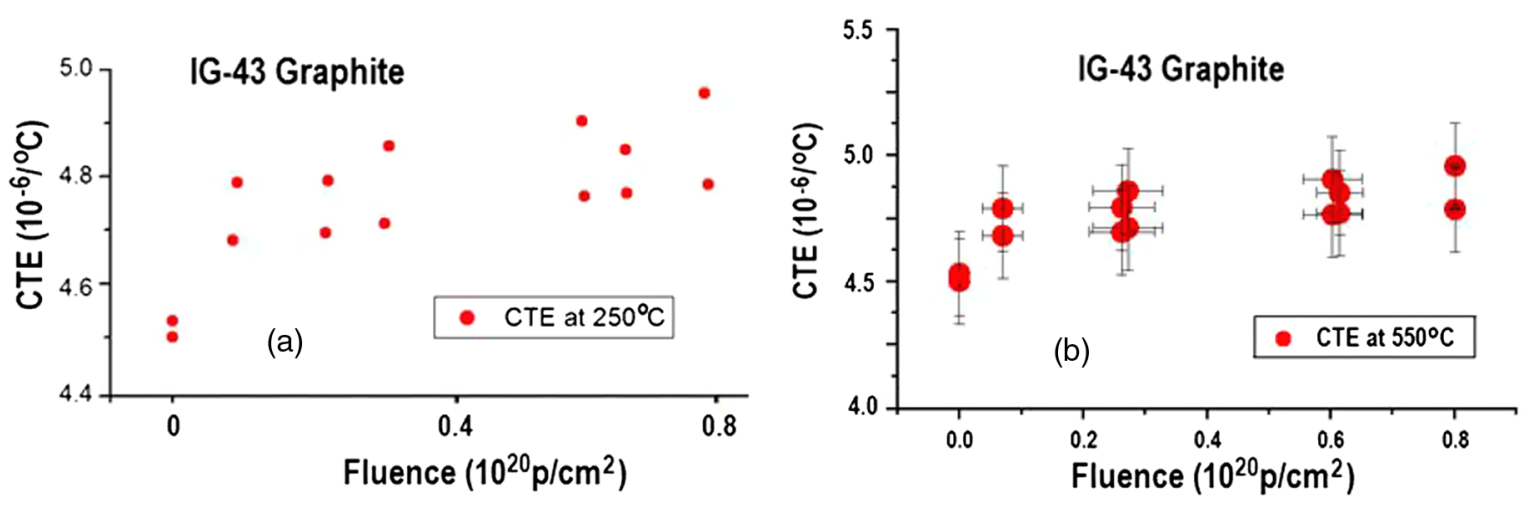

FIG. 7. CTE of IG-43 graphite as a function of proton fluence. (a) $250{ }^{\circ} \mathrm{C}$ and (b) $550{ }^{\circ} \mathrm{C}$.
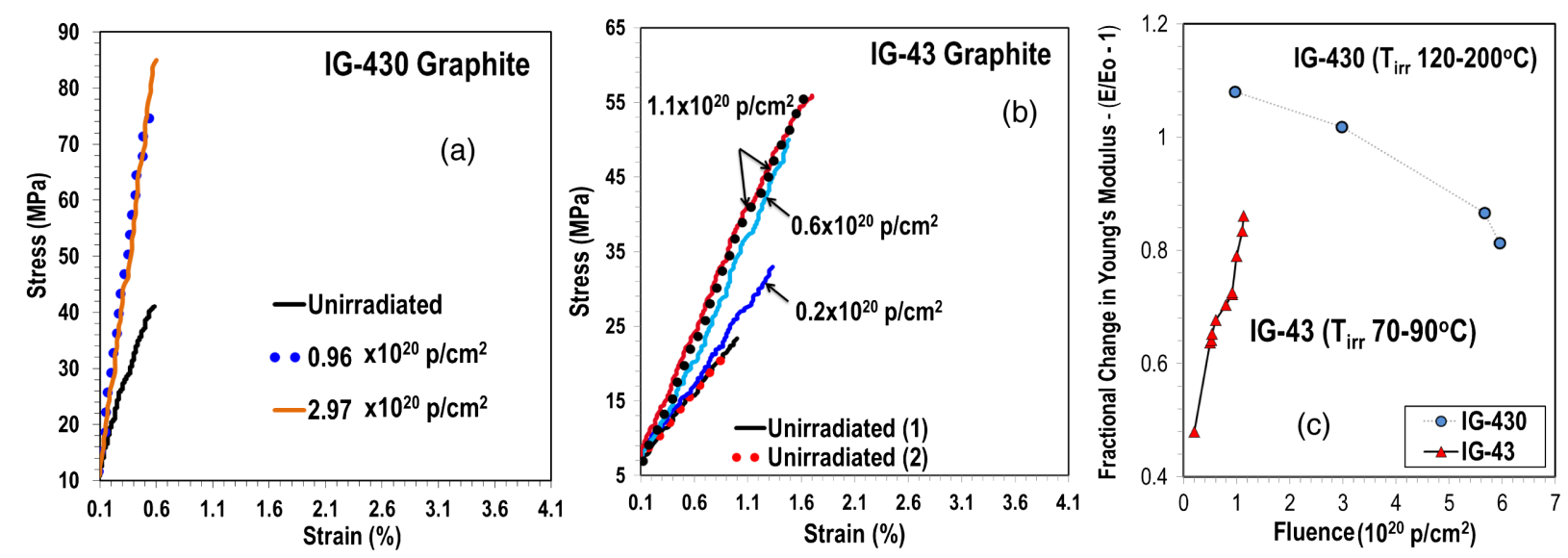

FIG. 8. Stress-strain relationship of IG-430 and IG-43 graphite grades. (a) IG-430, (b) IG-43, and (c) fractional Young's modulus change comparison.

interface between graphite and copper to take advantage of its strength. The three materials were to be joined with brazing under vacuum and with a silver insert layer to accommodate differences in thermal expansion coefficients with copper. The double joint (IG-43 to titanium and titanium to copper) showed excellent load performance prior to irradiation for two joint orientations tested, $90^{\circ}$ and $45^{\circ}$. Figure 9 (a) shows the $40 \mathrm{~mm}$ long with $45^{\circ}$ joint orientation of a test sample used in the loading tests as well as thermal analyses and subsequently proton irradiation. Figures 9(b) and 9(c) are SEM micrographs of the two interfaces (titanium to copper and titanium to graphite). In Fig. 9(d) also shown is the dimensional change of the samples for both orientations of the joints as well as those of the constituent materials. Important to note is the inability to separate copper from titanium at the brazed interface prior to irradiation. Irradiation using $200 \mathrm{MeV}$ protons at BLIP leading to peak fluence exceeding $8 \times 10^{20} \mathrm{p} / \mathrm{cm}^{2}$ at the central part of the beam has led to complete separation of the constituent materials at the two interfaces for both joint orientations as is clearly seen in Figs. 9(d) and 9(e).
To further explore the detrimental effects of proton irradiation on the two joints, $\mathrm{x}$-ray diffraction experiments were conducted at the X17B1 beam line of NSLS using $200 \mathrm{keV}$ polychromatic $\mathrm{x}$ rays on irradiated samples that were still intact. These samples were at $\sim 2 \sigma$ of the beam and were exposed to fluence of $\sim 8 \times 10^{20} \mathrm{p} / \mathrm{cm}^{2}$. The tight $\mathrm{x}$-ray beam was scanned across the two joints with reflections emanating deep from within the sample and not influenced by any surface effects (EDXRD technique).

Figure 10(a) presents the resulting 3D phase map and Fig. 14(b) reflections of the IG-43 graphite associated with this composite target as well as reflections of unirradiated and irradiated IG- 430 grade graphite (irradiated at $180^{\circ} \mathrm{C}$ to similar fluence) for comparison. The $\mathrm{x}$-ray diffraction demonstrates that for this fluence $\left(\geq 8 \times 10^{20} \mathrm{p} / \mathrm{cm}^{2}\right)$ the (002) reflection has all but disappeared, indicating that the graphite adjacent to the interface has become disordered (as pointed out by other studies on graphite irradiated by fast neutrons, [13]) leading to the observed joint failure. Follow-up irradiation and microstructural (x-ray) experiments are planned to fully understand the copper-titanium joint failure under proton irradiation. 

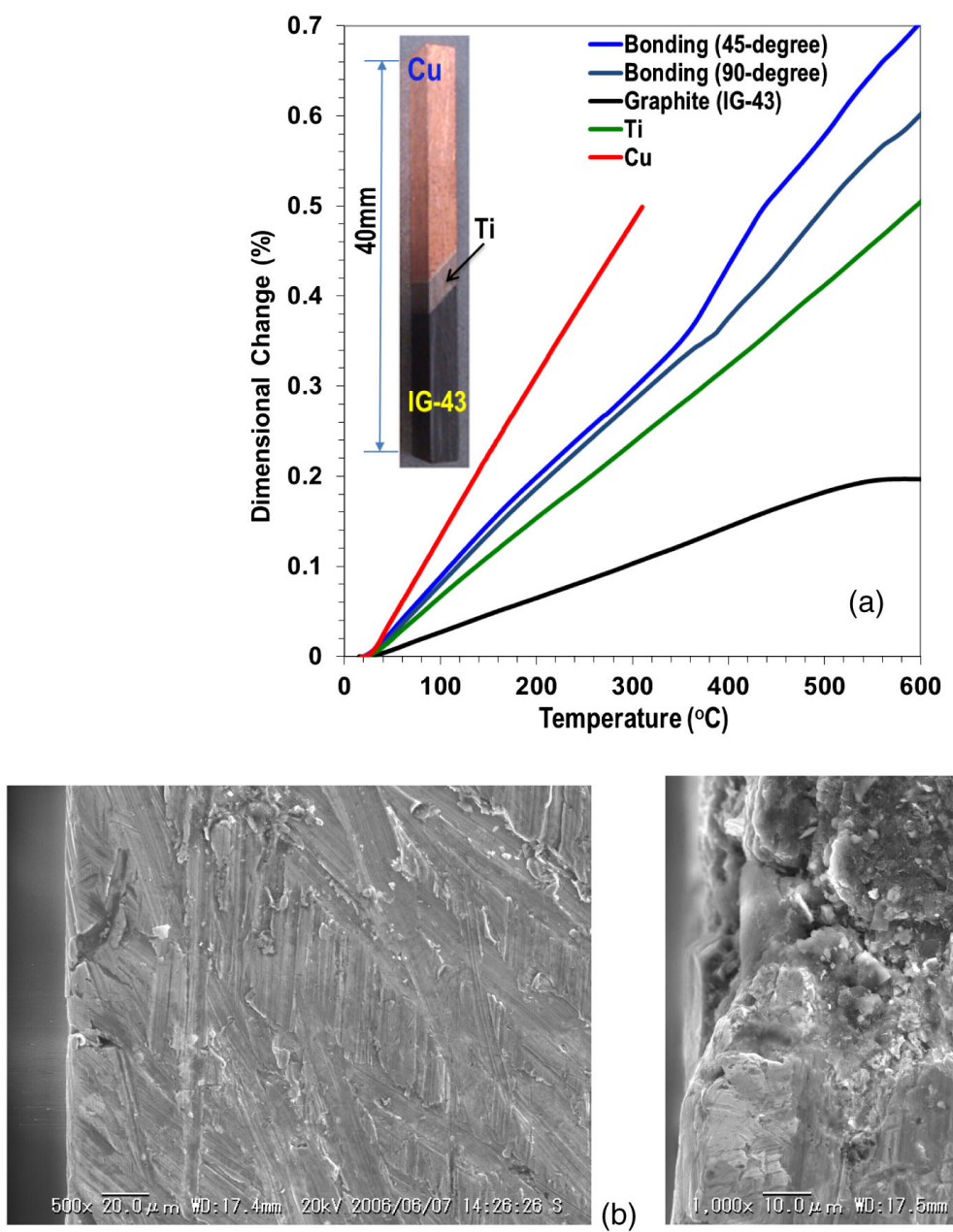

(b)

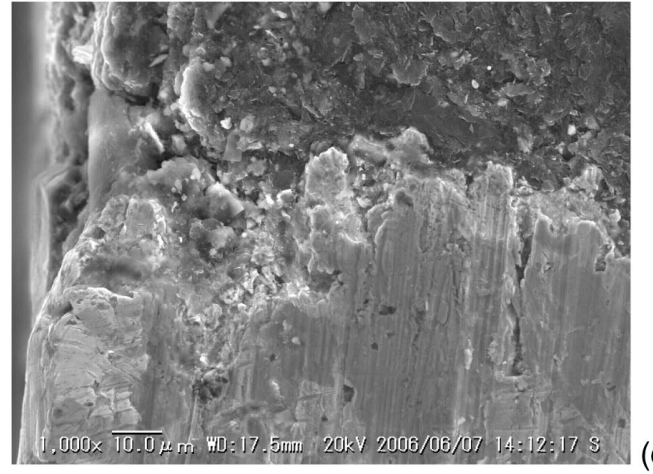

(c)
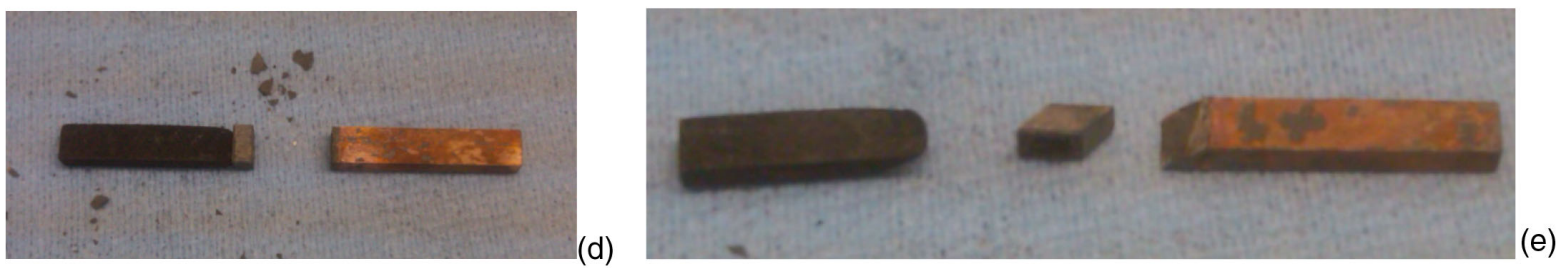

FIG. 9. Dimensional stability and irradiation effects on titanium to copper and titanium to graphite joints formed by brazing with silver insert layer at the interfaces. (a) Dimensional change of the composite structure and constituent materials, (b) SEM of titanium to copper interface (barely visible at the midheight of the micrograph), (c) IG-43 graphite to titanium interface, (d) failure of $90^{\circ}$ joint orientation due to proton irradiation, (e) failure of $45^{\circ}$ joint due to proton irradiation after reaching $8 \times 10^{20} \mathrm{p} / \mathrm{cm}^{2}$ fluence.

\section{B. Super-Invar, gum metal and Ti-6Al-4V damage studies}

Proton irradiation damage on three (3) superalloys were explored as target materials in the neutrino factory initiative and are presented herein. These include Invar 32-5 (or superInvar) the $(\alpha+\beta)$ Ti-6Al-4V alloy and the $\beta$-titanium alloy known as gum metal. Properties of interest in these superalloys (other than pion yield and spectra) are their mechanical strength as well as their dimensional and phase stability.

Super-Invar.-Without the presence of irradiation, the invar effect, i.e. the low thermal expansion of invar alloys, stems from the balance between the thermal expansion and contraction due to a large positive, spontaneous volume magnetostriction and magnetization anomalies that occur below the Curie temperature. The superp-Invar alloy that was studied exhibits extremely low CTE up to $\sim 140^{\circ} \mathrm{C}$ (a property that if unaffected by long irradiation exposure) will prevent the transient thermal stresses on the target from reaching unacceptable values. The irradiation studies aimed towards the understanding of the resilience of this alloy in maintaining the low CTE even with the presence of proton radiation.

The irradiation of super-Invar took place in three stages between which post-irradiation annealing was conducted to 


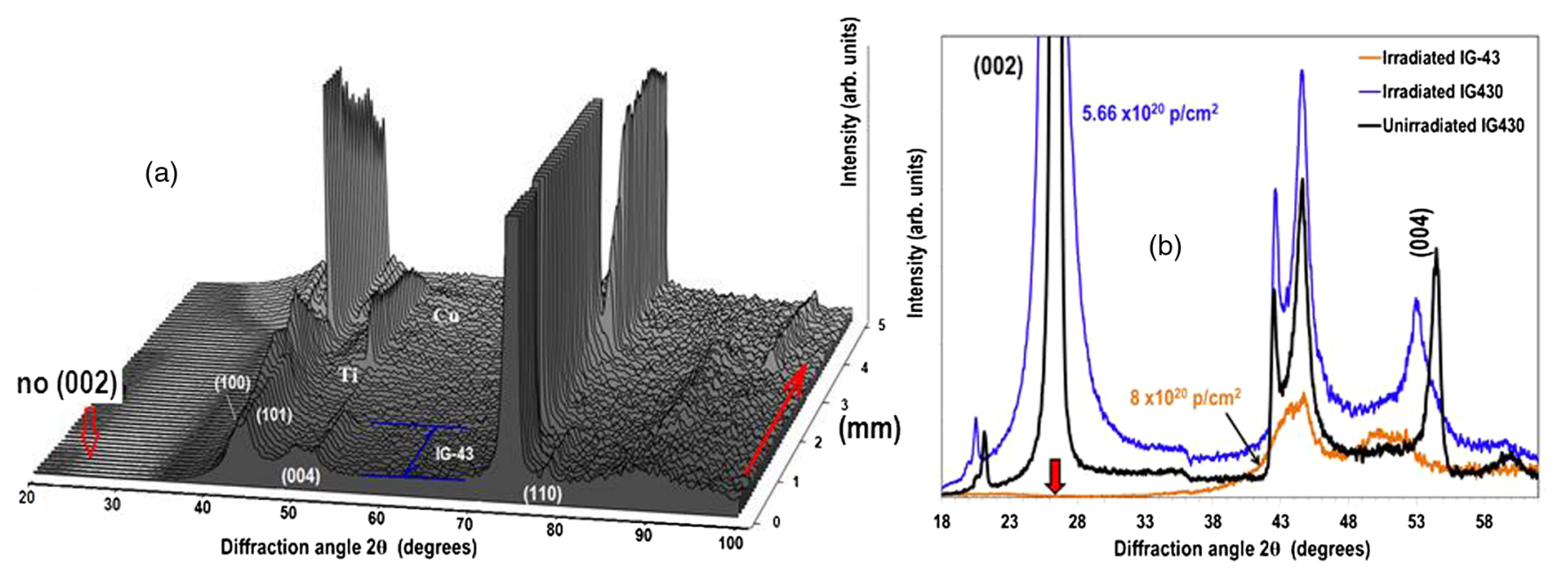

FIG. 10. X-ray diffraction of irradiated Cu-Ti-graphite J-PARC muon facility target. (a) Phase map across the two interfaces. (b) Comparison of reflections between the irradiated IG-43 graphite section and irradiated IG-430 graphite grade.

observe potential restoration of its unique properties through annealing. Specifically, following the first irradiation phase to peak fluence $1.13 \times 10^{20} \mathrm{p} / \mathrm{cm}^{2}$ it was observed that the low thermal expansion between room temperature and $140{ }^{\circ} \mathrm{C}$ has been affected by proton irradiation as seen in Fig. 11(a). Several thermal cycles with increasing peak temperature $\left(200{ }^{\circ} \mathrm{C}, 300^{\circ} \mathrm{C}, 400{ }^{\circ} \mathrm{C}\right.$, $400^{\circ} \mathrm{C}, 550^{\circ} \mathrm{C}$ and $600^{\circ} \mathrm{C}$ ) were conducted revealing that full restoration of the preirradiated behavior is achieved following annealing to $600{ }^{\circ} \mathrm{C}$ [Fig. 11(b)] super-Invar samples that were annealed following the first irradiation phase were reintroduced to the proton beam for additional dose. Remarkably, as shown in Fig. 12 the irradiatedannealed-irradiated super-Invar samples lost the "invar" effect again only to see it restored upon the second annealing. The same pattern held true for a subsequent third irradiation phase. Figure 13 depicts irradiation and thermal treatment effects on the stress-strain behavior of super $=$ Invar. As noted in Fig. 13(a) the Fe-Ni alloy exhibits resistance against radiation-induced ductility loss. Heat treatment at $300{ }^{\circ} \mathrm{C}$ and $500{ }^{\circ} \mathrm{C}$ have different effects on the alloy with the $500{ }^{\circ} \mathrm{C}$ resulting in higher ductility and reduction of strength.

Micro-characterization of the super-Invar alloy following irradiation and using x-ray diffraction (Fig. 14) revealed that (a) a second fcc phase appears in the alloy as a result of irradiation (possibly aided by post-irradiation thermal annealing) referred to as "paramagnetic" phase and (b) the two fcc phases (Ni rich and Fe rich) are stable following irradiation, subsequent annealing and reirradiation. Figure 14
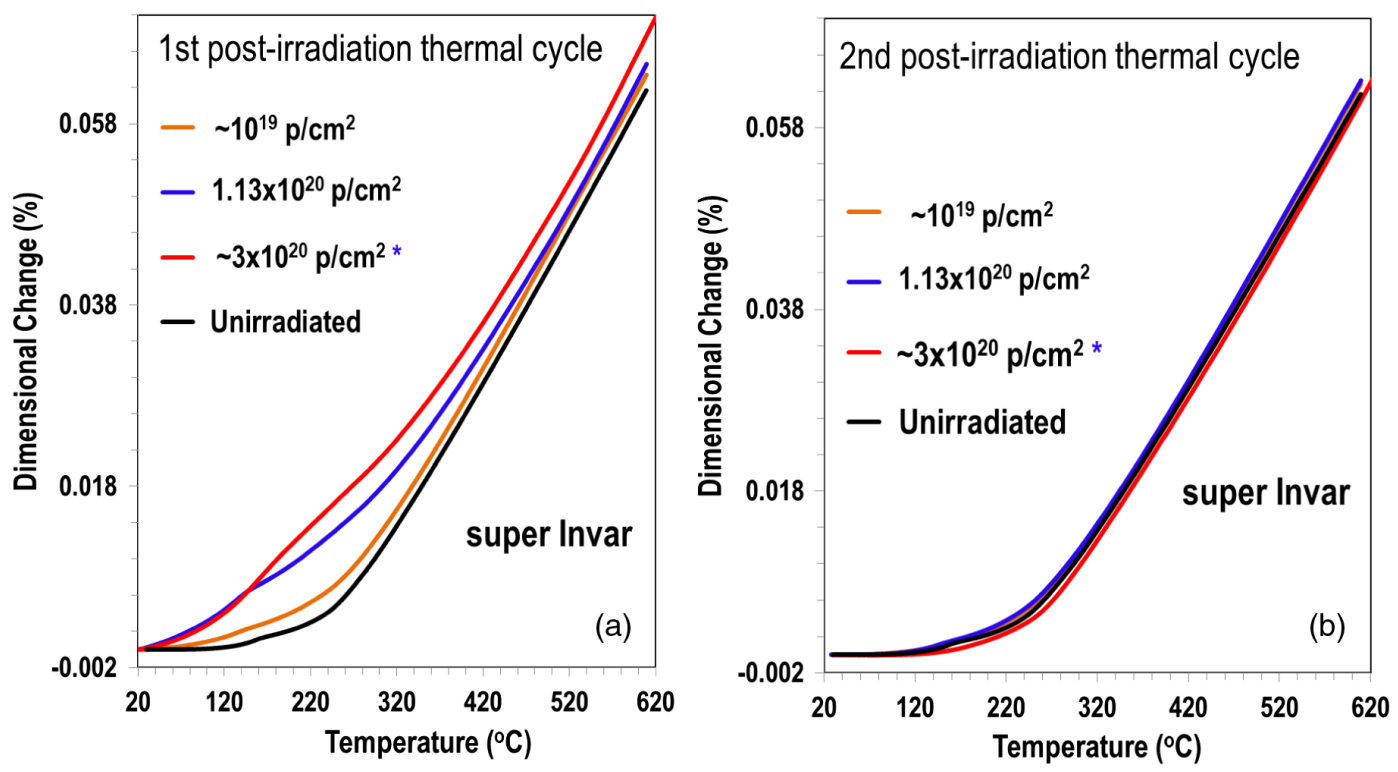

FIG. 11. Super-Invar post-irradiation damage reversal. (a) first post-irradiation and (b) second post-irradiation thermal cycles. 


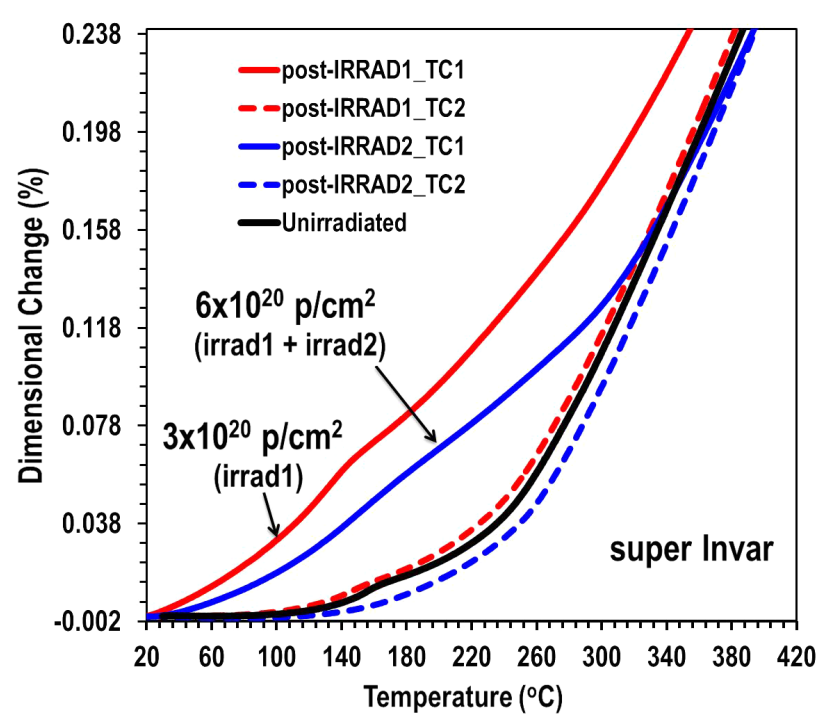

FIG. 12. Super-Invar post-irradiation damage reversal.

confirms the presence of $\mathrm{Co}$, the bcc phase and the two fcc phases.

Gum metal.-This $\beta$-type multifunctional alloy in "as-annealed" and 90\% cold-worked states was evaluated following proton irradiation to a peak fluence of $\sim 0.8 \times 10^{20}$ and $1.13 \times 10^{20} \mathrm{p} / \mathrm{cm}^{2}$ respectively. Shown in Fig. 15 [19] is the mechanical behavior at room temperature of the alloy depicting its outstanding elongation to failure. It is the remarkable properties at room temperature [i.e. strength, low E modulus and superplasticity as well as Invar-like behavior, Fig. 15(a), to a wider temperature range, up to $400{ }^{\circ} \mathrm{C}$ ] that prompted these studies to observe how these unique properties hold under irradiation and high temperatures expected in a solid target.
As seen in Fig. 15(a), a transformation is taking place in the temperature range of $400^{\circ} \mathrm{C}-580^{\circ} \mathrm{C}$.

Thermal analysis consisting of several thermal cycles to temperatures $\sim 650^{\circ} \mathrm{C}$ of unirradiated and proton-irradiated 90\% cold-worked gum metal revealed (see Fig. 16) that the thermal expansion and CTE of this $\beta$-alloy when traversing the phase transformation temperature regime is influenced only by temperature and not irradiation. The important finding of the present study is that a single pass destroys the invar effect almost entirely. It is important to also note that, while during the cooling phase of the first thermal cycle denoted as TC1-cooling in Fig. 16, the alloy behaves as a normal material (indicated by the straight trace during cooling), during the heating phase of the second thermal cycle (TC2) the alloy exhibits a faint "memory" of the phase transition which is not again evident during cooling.

The CTE of the as-annealed gum metal [or noted as "as-solution treated" in Fig. 15(b)] is depicted in Fig. 17(a) as a function of fluence at $550^{\circ} \mathrm{C}$ indicating an increase followed by a leveling off with dose. The data, however, that are highly relevant to accelerator target response (stress strain and ductility loss) are depicted in Fig. 17(b) which shows the dramatic change of the stress-strain relationship of this $\beta$-alloy. What is shown is that even modest proton fluences $\left(\sim 1.13 \times 10^{20} \mathrm{p} / \mathrm{cm}^{2}\right)$ can transform this superelastic, superductile material to one that is completely brittle.

To shed some light into this dramatic change that occurs under irradiation, x-ray diffraction experiments were conducted at NSLS-X17B1 and NSLS II-XPD beam lines. It is evident from Fig. 18(a) that during irradiation $\alpha^{\prime \prime}$ (orthorhombic) martensite nanodomains form in both the as-annealed and the cold-worked states of the material thus changing the microstructure. Preexisting martensite domains are identified in Fig. 18(b) using the $67 \mathrm{keV}$ x rays

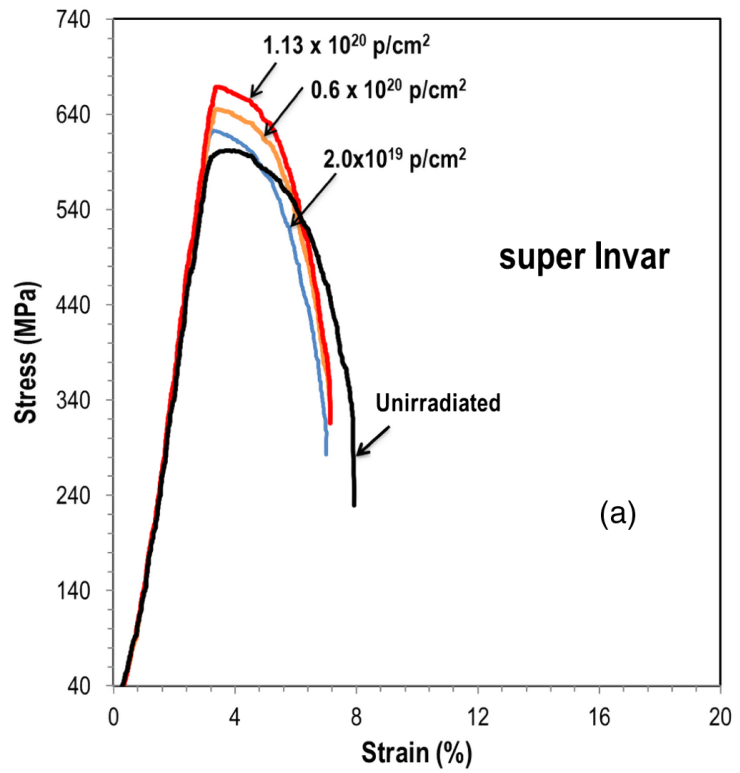

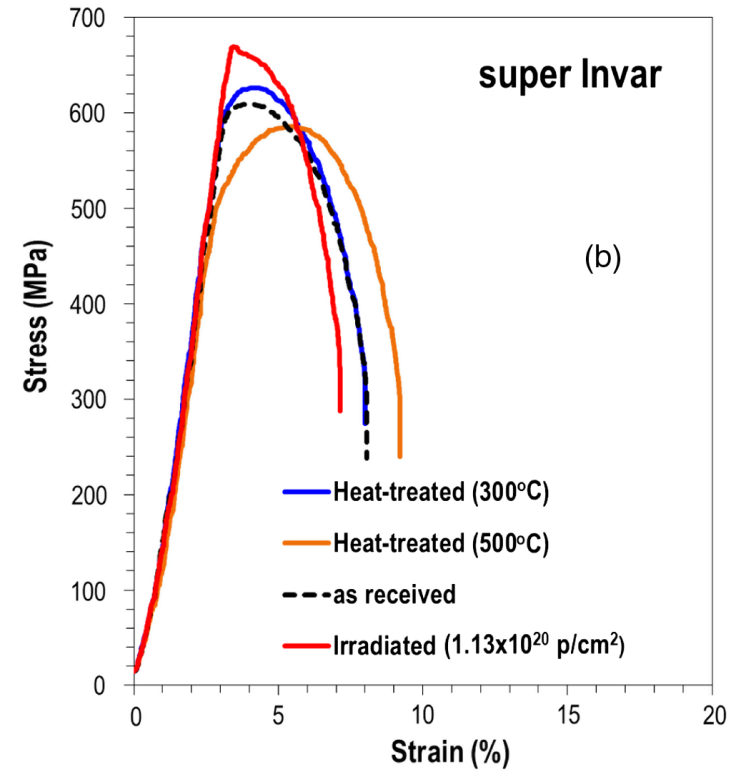

FIG. 13. Super-Invar irradiation and temperature treatment effects on stress-strain behavior. (a) irradiation effects and (b) temperature effects. 

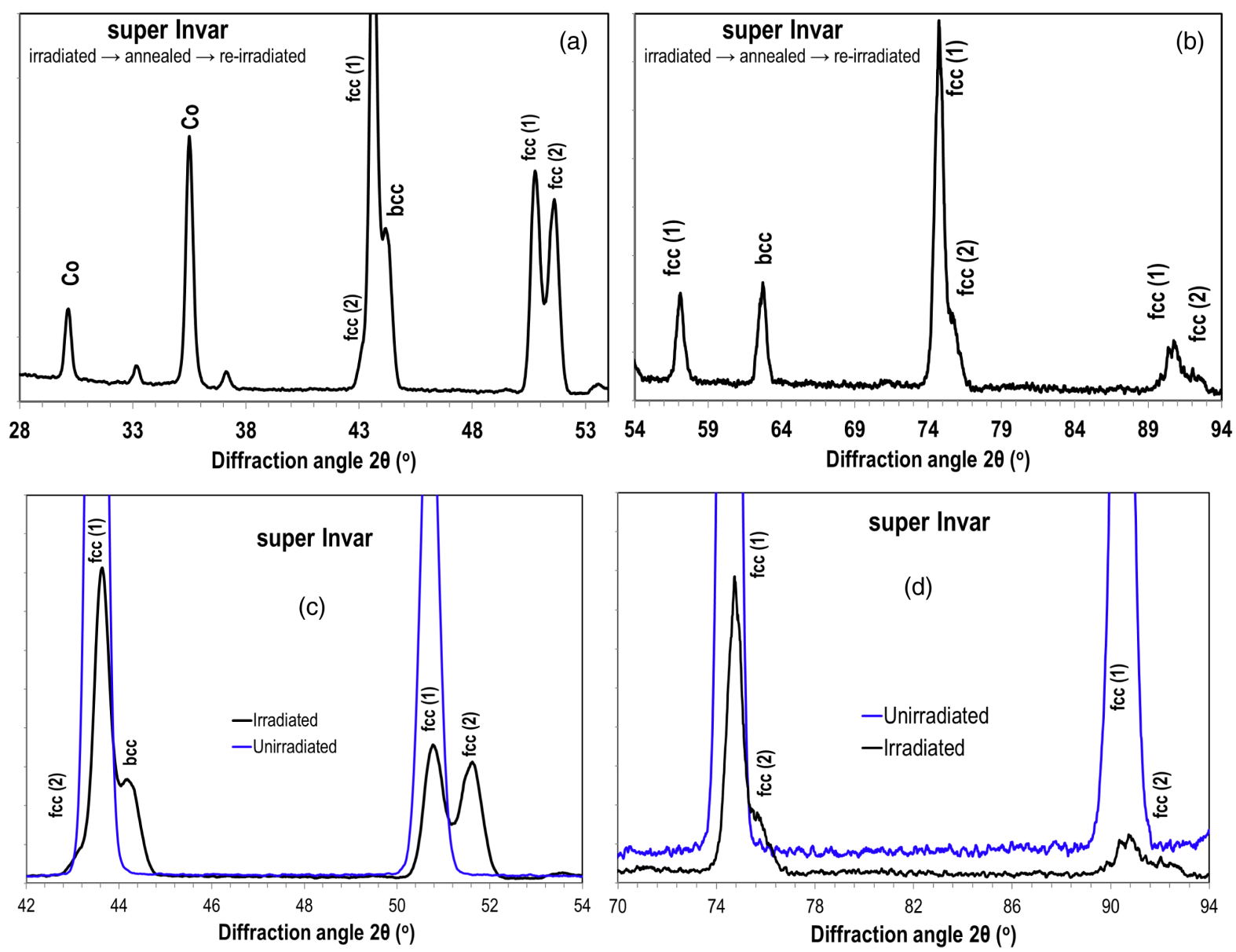

FIG. 14. Phase identification in proton-irradiated, annealed super-Invar to a fluence of $\sim 3 \times 10^{20} \mathrm{p} / \mathrm{cm}^{2}$. (a) and (b) Comparison with unirradiated super-Invar. (c) and (d) Revealing the appearance of the second $f c c$ phase.

at the NSLS II XPD beam lines, an important finding in that it can help settle the on-going debate on the responsible deformation mechanisms [19,33]. The microstructural changes occurring during plastic deformation of the unirradiated $90 \%$ cold-worked gum metal alloy are depicted in Fig. 19.

Ti-6Al-4V.- In the present study irradiations at BNL BLIP to a peak fluence of $1.147 \times 10^{20} \mathrm{p} / \mathrm{cm}^{2}$ were conducted at $\mathrm{T}_{\text {irr }} \sim 240^{\circ} \mathrm{C}$ (estimated from numerical analysis [31]) aiming to assess dimensional stability, hardening and microstructural changes. Figure 20(a) depicts dimensional changes for the unirradiated and proton-irradiated Ti$6 \mathrm{Al}-4 \mathrm{~V}$. As noted both states are characterized by similar trends in both heating and cooling phases of the thermal cycle. During the cooling phase of the $610^{\circ} \mathrm{C}$ peak temperature cycle the material exhibits a constant CTE (constant
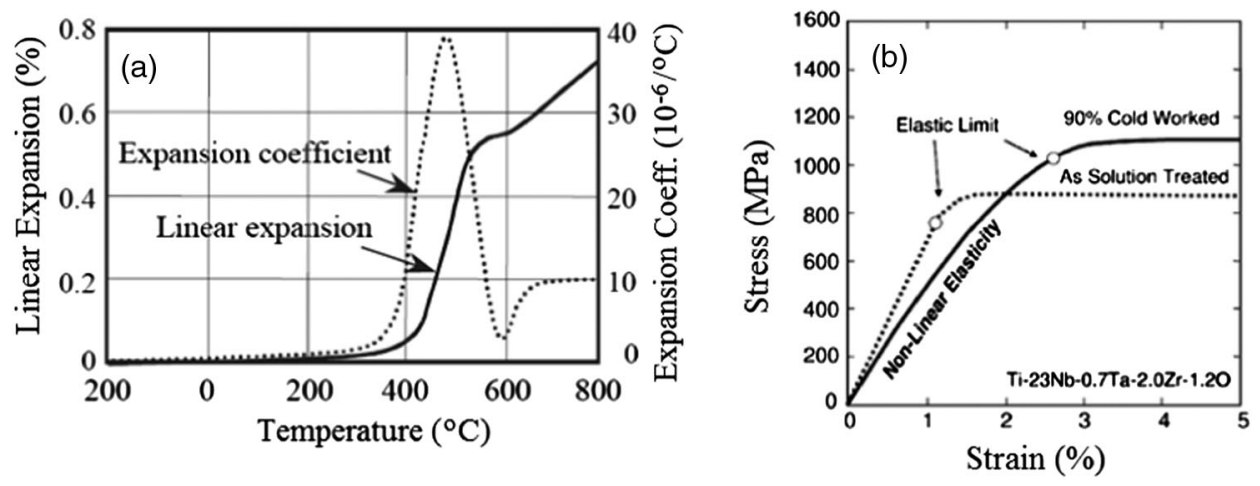

FIG. 15. Gum metal alloy (a) thermal and (b) mechanical properties [19]. 

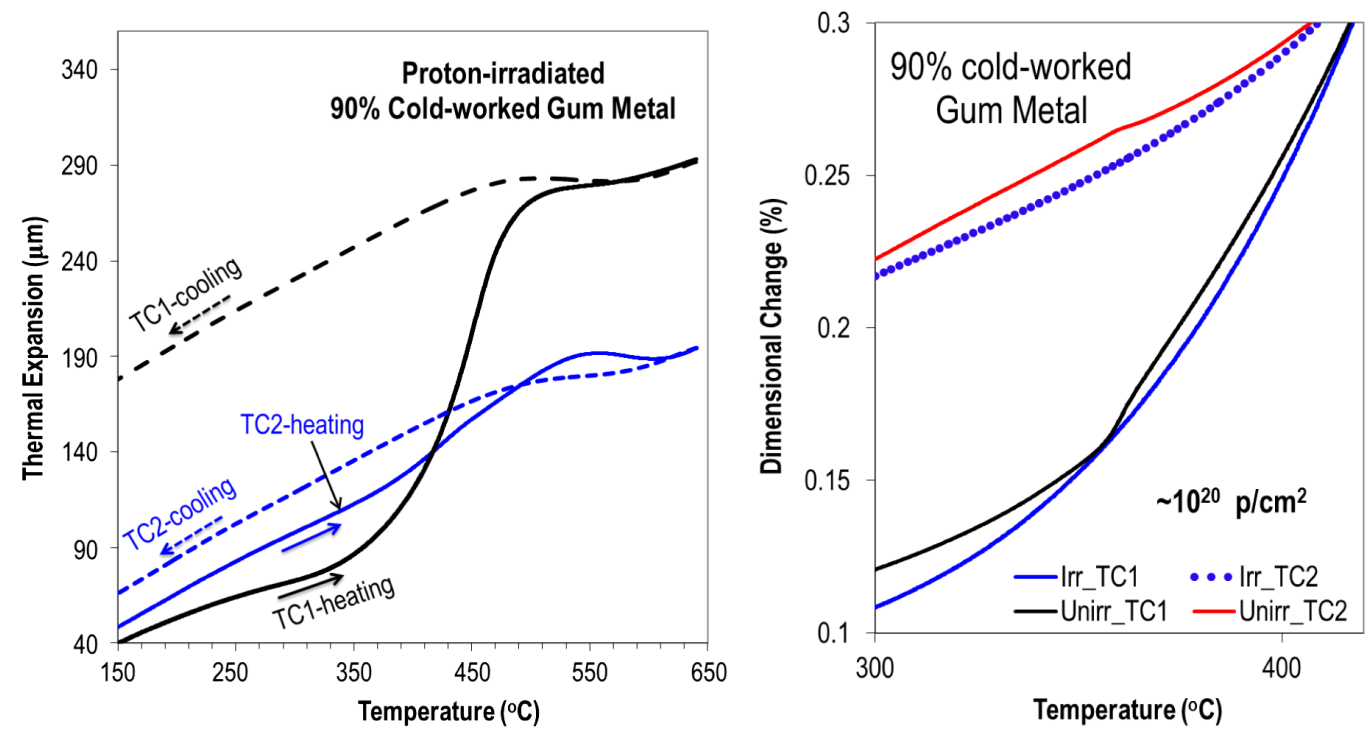

FIG. 16. Irradiation and temperature effects on the thermal expansion coefficient of gum metal.
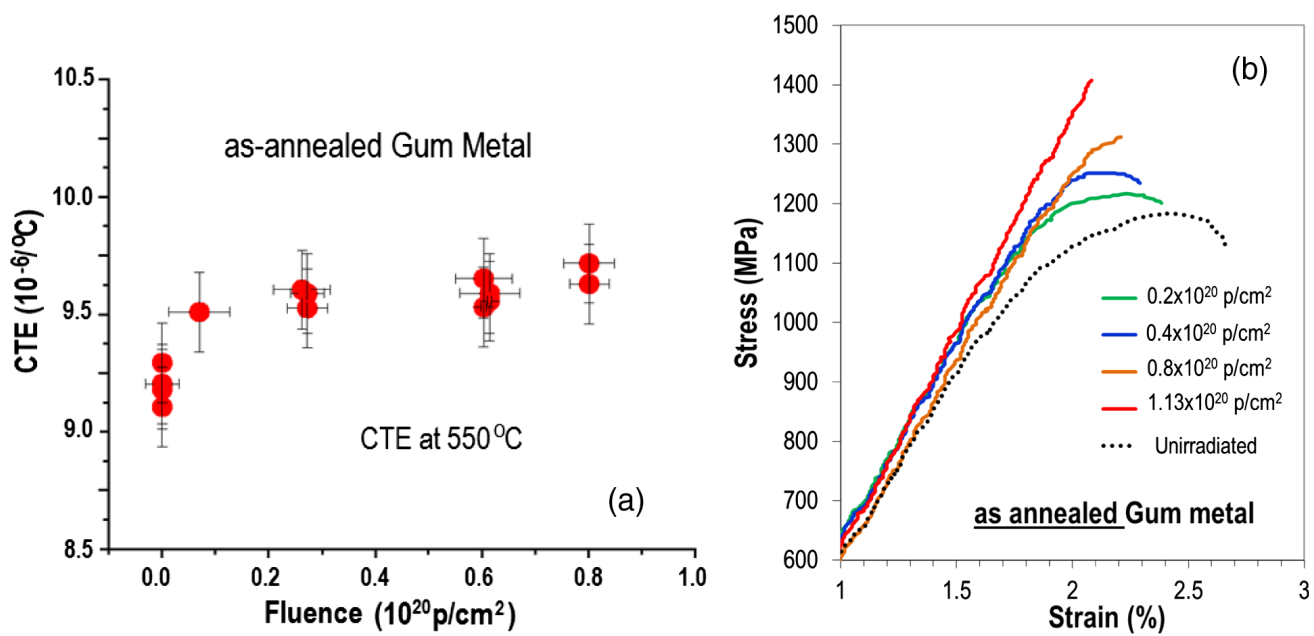

FIG. 17. Irradiation effects on (a) CTE and (b) ductility of "annealed" gum metal.
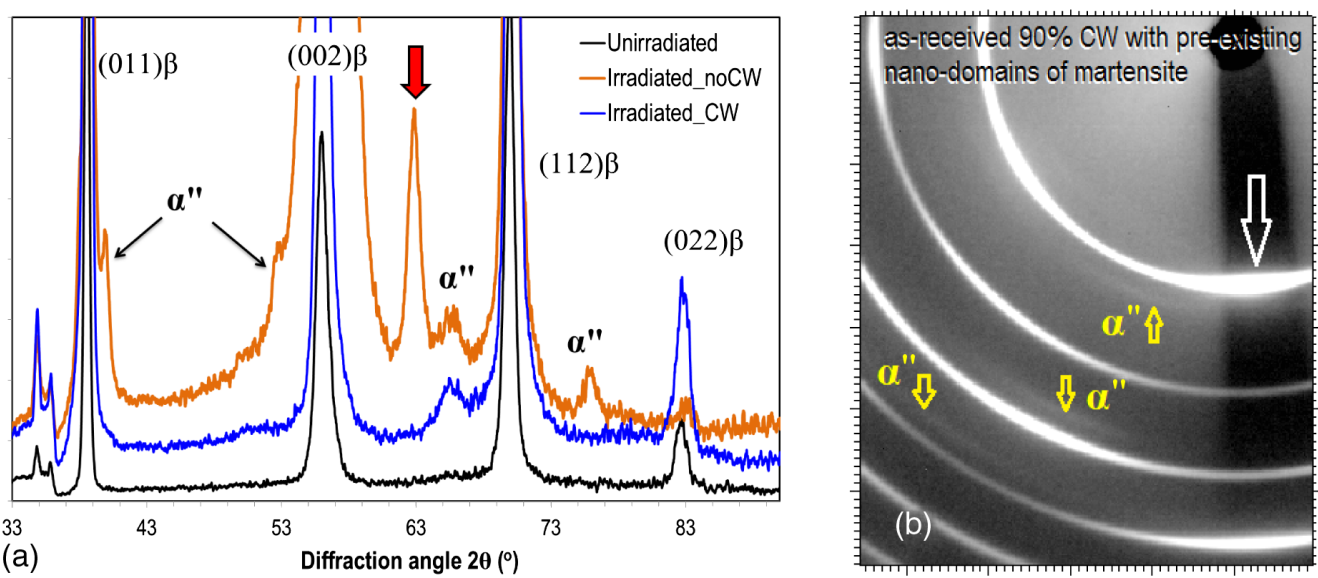

FIG. 18. (a) Observed phases and their evolution with irradiation in gum metal and (b) revealed presence of $\alpha^{\prime \prime}$ (orthorhombic) martensite nanodomains in $90 \%$ cold-worked gum metal and microstructure texture resulting from cold working. 

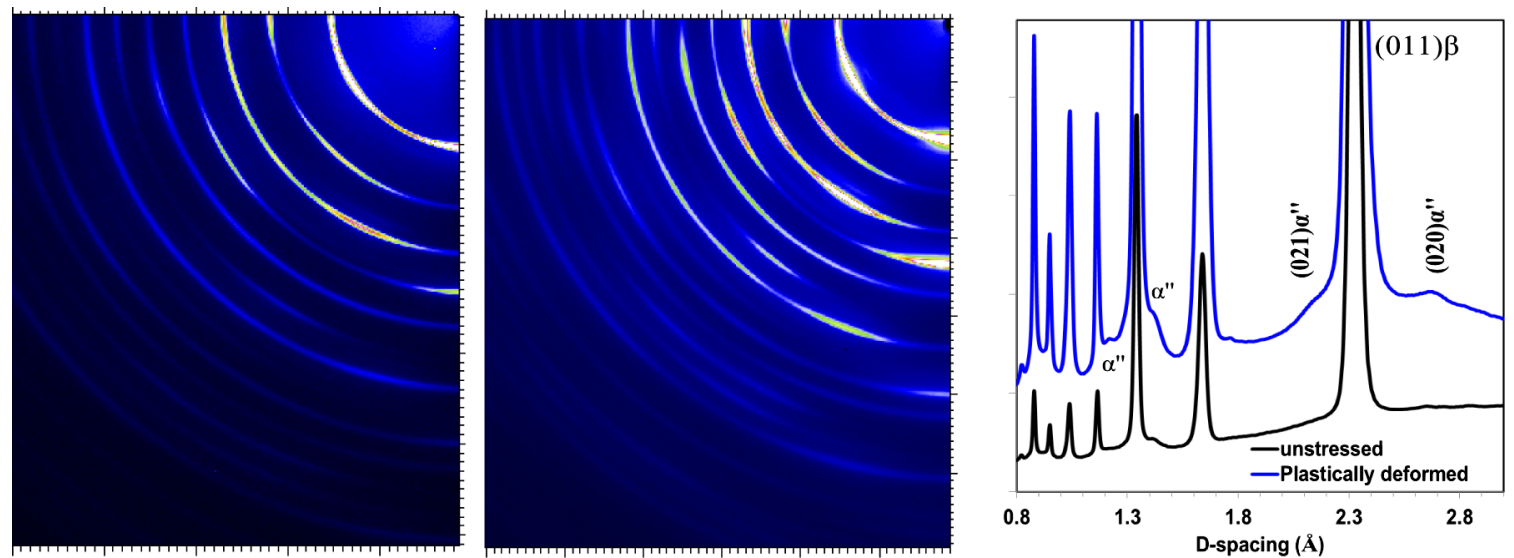

FIG. 19. Unstrained (left), plastically deformed (middle) and phase map of 90\% cold-worked gum metal revealing $\alpha^{\prime \prime}$ transformations occurring during plastic deformation.

slope of the dimensional change trace). Figure 20(b) shows the $\mathrm{CTE}$ at $550^{\circ} \mathrm{C}$ as a function of fluence. The stress-strain behavior and irradiation-induced hardening of Ti-6Al-4V is depicted in Fig. 21(a) (for protons) and Fig. 21(b) for neutrons [22]. The neutron irradiations in [22] were conducted at $50{ }^{\circ} \mathrm{C}$ and $350{ }^{\circ} \mathrm{C}$ temperatures reaching displacement damage of $\sim 0.3 \mathrm{dpa}$ (displacements per atom). Neutron irradiation induced hardening, plastic instability and a substantial reduction in fracture toughness due to irradiation-induced precipitation. The peak proton fluence of this study $\left(1.147 \times 10^{20} \mathrm{p} / \mathrm{cm}^{2}\right)$ is estimated to correspond to $\sim 0.25$ dpa providing a good basis of comparison that is depicted in Fig. 21 where similar hardening behavior is observed between the different irradiating species (protons and neutrons).

In [23] tension/compression asymmetry, anisotropic yielding and anisotropic strain hardening in the Ti-6Al$4 \mathrm{~V}$ were observed. The effects of irradiation in altering such tension-compression asymmetry at the crystallographic level were explored in this study using high energy $\mathrm{x}$-ray diffraction. This was achieved by subjecting unirradiated and irradiated tensile test specimens [Fig. 1(a)] to a high in situ stress state (compression and tension) using a four-point-bending configuration during x-ray irradiation. Figure 22(a) depicts phase evolution in the Ti-6Al-4V as a function of proton fluence. As seen in Fig. 22(a), other than the broadening of the diffraction peaks, no new phases or disappearance thereof are observed. Under four-pointbending stress, however, shown in Fig. 22(b), significant anisotropy at the crystallographic level is observed attributed to be the result of the hcp-type structure and the interaction of alpha and beta phases.

\section{Tantalum and tungsten damage studies}

Tantalum and tungsten CTE and tensile specimens (Fig. 1) were irradiated at BLIP to a peak fluence of $5.14 \times 10^{20} \mathrm{p} / \mathrm{cm}^{2}$ in deionized water with peak irradiation temperatures $\sim 400{ }^{\circ} \mathrm{C}$ (estimated). Apart from radiation damage induced in the microstructure of tantalum and tungsten, the resistance to corrosion/erosion of these materials in the presence of radiolysis products due to the interaction of the beam with water is an important target design parameter. Shown in Fig. 23 is the material loss in
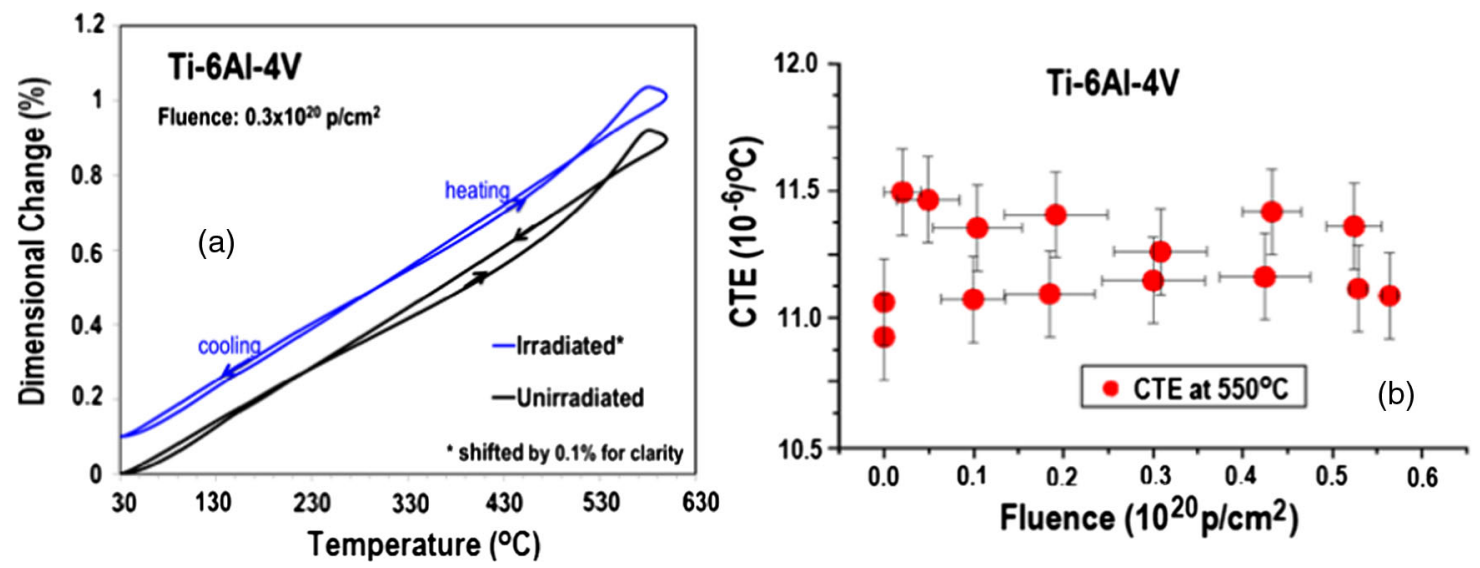

FIG. 20. Proton irradiation effects on (a) dimensional stability, (b) CTE at $550{ }^{\circ} \mathrm{C}$ of Ti-6Al-4V. 

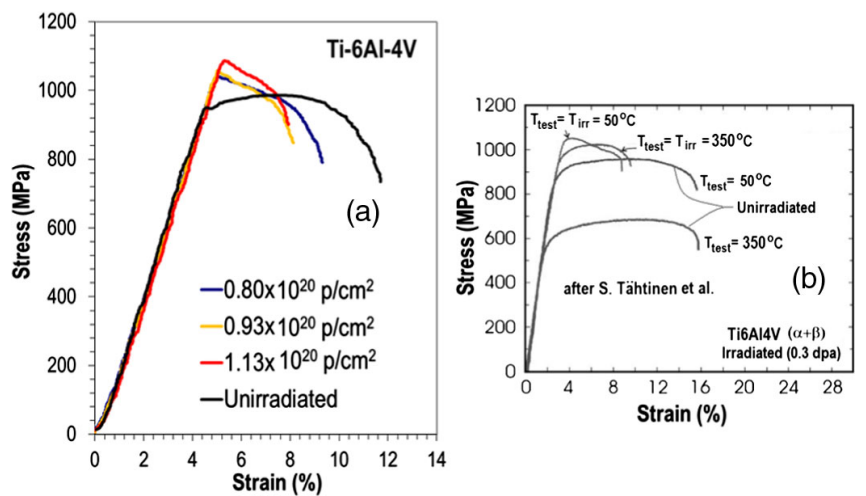

FIG. 21. (a) Proton irradiation dose ( $\sim 0.25$ dpa maximum) on Ti-6Al-4V stress-strain behavior compared to (b) neutron effects on stress strain [22].

tungsten irradiated at $\sim 400{ }^{\circ} \mathrm{C}$ to the peak fluence $5.14 \times 10^{20} \mathrm{p} / \mathrm{cm}^{2}$. The measured weight loss of $\sim 50 \%$ qualitatively agrees with results reported in [35] where the corrosion rate of tungsten was found to be high under $800-\mathrm{MeV}$ proton irradiation in water. No corrosion was observed for tantalum irradiated under the exact same conditions with those of tungsten.

Figure 24 depicts dimensional changes and the CTE of unirradiated and irradiated tungsten up to $600{ }^{\circ} \mathrm{C}$ temperature in air (rough vacuum that was slowly contaminated with air due to a crack developed in the quartz tube). The $S_{1}$ location indicated by the arrow points to what appears to be a subtle transition for both the irradiated and unirradiated tungsten. This is depicted more clearly in Fig. 24(b) which shows the dimensional change of three consecutive thermal cycles. As seen in Fig. 24 the CTE of tungsten is largely unaffected by irradiation for the dose levels achieved in these experiments.

Turning to the nature of the "anomaly," and since there is no evidence to suggest that any change in crystal structure or lattice rearrangement is taking place, is assessed by the authors to be electronic in origin. Changes or anomalies in

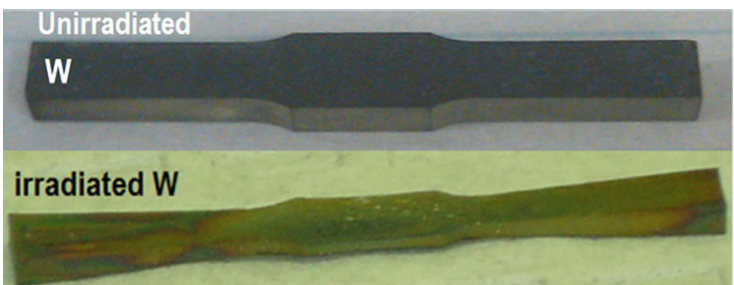

FIG. 23. Observed erosion of tungsten CTE sample irradiated to an average fluence of $\sim 4 \times 10^{20} \mathrm{p} / \mathrm{cm}^{2}$ and $\mathrm{T}_{\text {irr }}$ of $\sim 400^{\circ} \mathrm{C}$ while cooled at the surface by water. Measured weight loss was $\sim 50 \%$.

other physical properties and anomalies at the same temperature will support the notion that the observed anomalous behavior is related to the onset of antiferromagnetism that is potentially influenced by impurities that affect the location of the narrow temperature range. Similar anomalous behavior or transformation has been observed [36] in tungsten trioxide $\left(\mathrm{WO}_{3}\right)$.

To understand the origin or the root cause and assess whether it is a behavior common to refractory metals or oxygen or other impurities specific experiments were conducted. Figure 25(a) shows tungsten lattice parameter changes as a function of temperature produced at NSLS using $\mathrm{X}$-ray diffraction in air indicating the presence of an anomaly over the temperature range $\left(340^{\circ} \mathrm{C}-350^{\circ} \mathrm{C}\right)$. To exclude that it is the formation of oxides affecting the lattice so dramatically, even at this low temperature, differential scanning calorimetry (DSC) where oxygen was eliminated and not a potential factor was conducted. Figure 25(b) is showing clearly the presence of a phase transition occurring over the same narrow temperature range. Unpublished results [37] explore the formation of tungsten oxides and the several transitions exhibited by $\mathrm{WO}_{3}$ to temperatures up to $960{ }^{\circ} \mathrm{C}$ correlating dilatometry, differential scanning calorimetry and x-ray diffraction. Results in [37] confirmed the observations reported in [36].
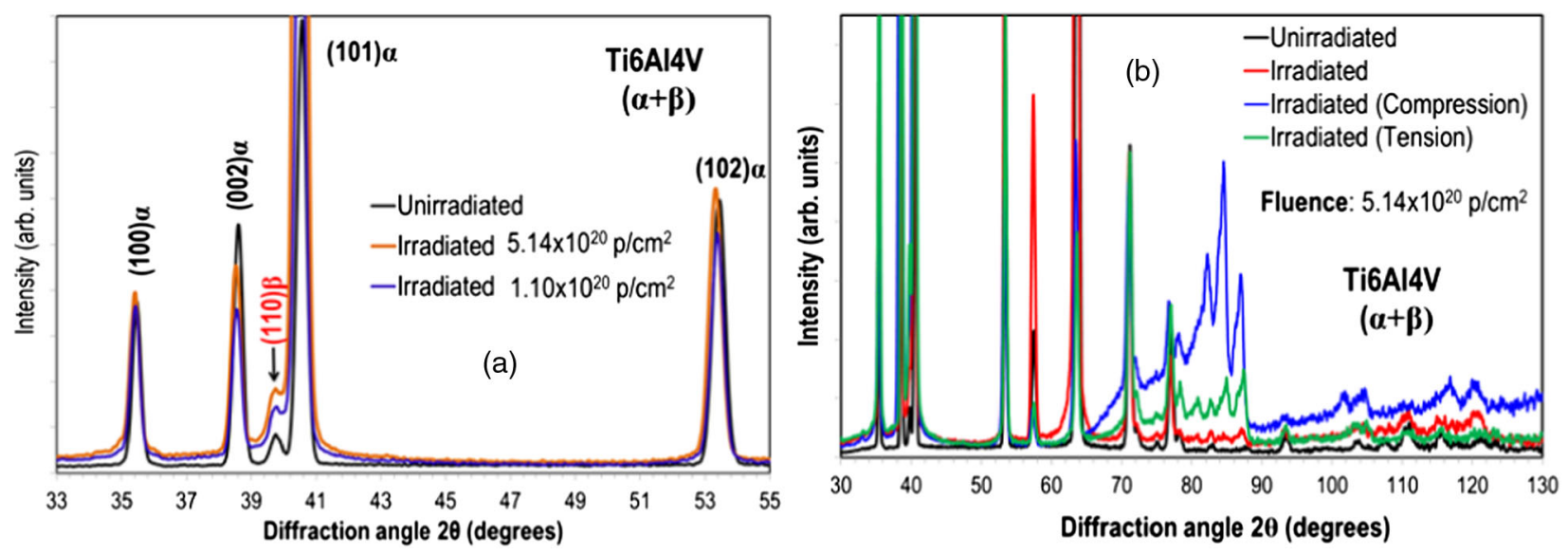

FIG. 22. Stability of $\alpha$ and $\beta$ phases of Ti-6Al-4V following irradiation (a) and asymmetry between tension and compression. 

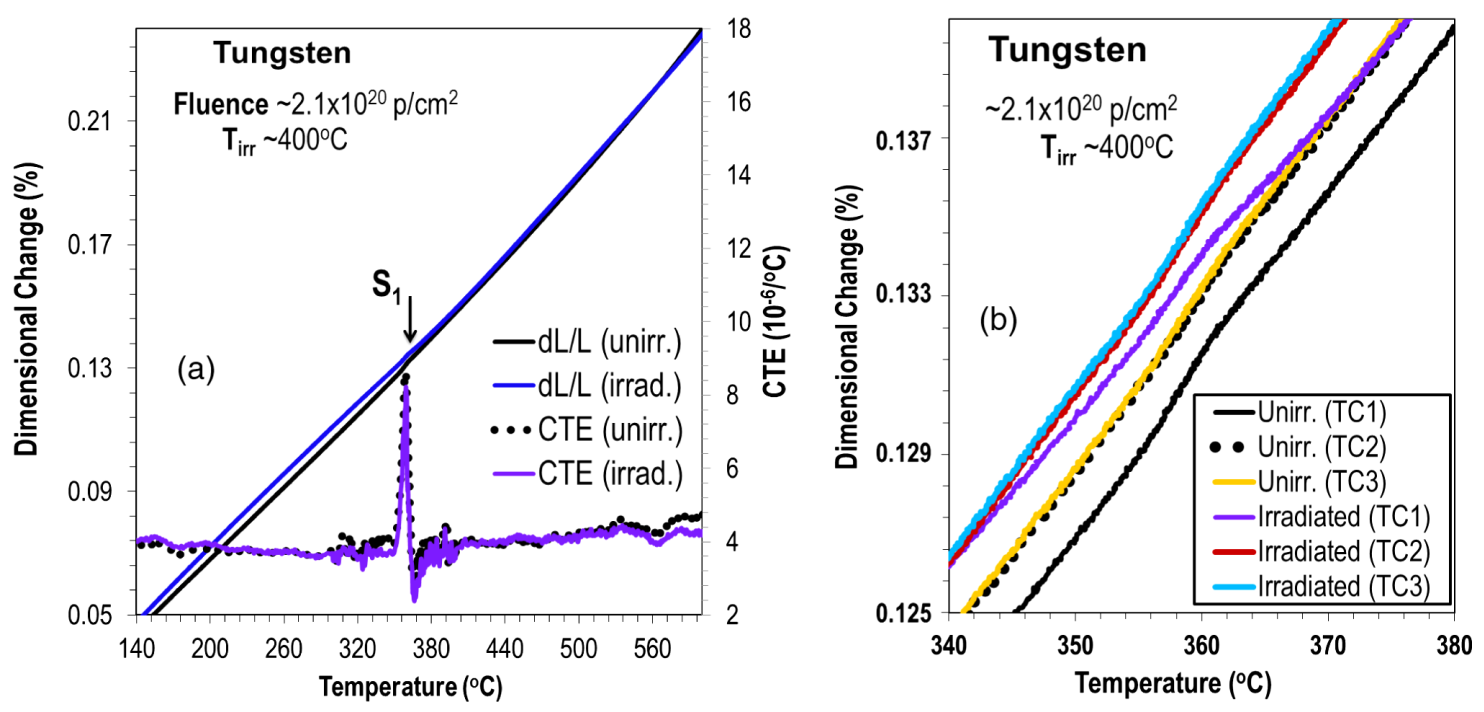

FIG. 24. Dimensional change and CTE of tungsten in (a) the temperature range $140-600^{\circ} \mathrm{C}$ and (b) $340-380{ }^{\circ} \mathrm{C}$.

Figure 26 depicts dimensional stability and CTE of tantalum as a function of temperature and dose. The presence of the subtle anomaly observed in tungsten is also evident in this refractory metal [Figs. 26(a) and 26(b)] reinforcing the assessment of the onset of a paramagneticantiferromagnetic transition that was observed for tantalum in [32]. As noted, however, in several studies [37,38] tantalum begins to oxidize above $300{ }^{\circ} \mathrm{C}$ which could imply that the anomaly shown at low temperature $\left(\sim 350^{\circ} \mathrm{C}\right)$ is the result of both effects, namely antiferromagnetic transition and oxidation. Shown clearly [Fig. 26(a)] is the onset of rapid oxidation of $\mathrm{Ta}$ above $550{ }^{\circ} \mathrm{C}$ where the stable $\mathrm{Ta}_{2} \mathrm{O}_{5}$ is formed. Stemming from Fig. 26(a) proton irradiation appears to lower the temperature where high oxidation rates are triggered. Irradiation dose levels, however, appear not to influence the temperature of the transition that is also attributed to be related to antiferromagnetism [Fig. 26(b)].

The effects of proton irradiation on the stress strain and hardening of tungsten and tantalum are depicted in Fig. 27. As shown in Fig. 27(a), tungsten, even at its unirradiated state, is very brittle. Subsequently, for the proton doses (up to $3.6 \times 10^{20} \mathrm{p} / \mathrm{cm}^{2}$ ) and room temperature tensile test temperatures all specimens failed in a brittle manner, often at stresses far below the yield stress of the unirradiated material. Similar observations for tungsten tensile failure was reported in [27] where, following fast neutron irradiation, tungsten failed at stresses far below the yield stress of the unirradiated material. Such behavior was attributed in [27] to the radiation-induced segregation of impurities at
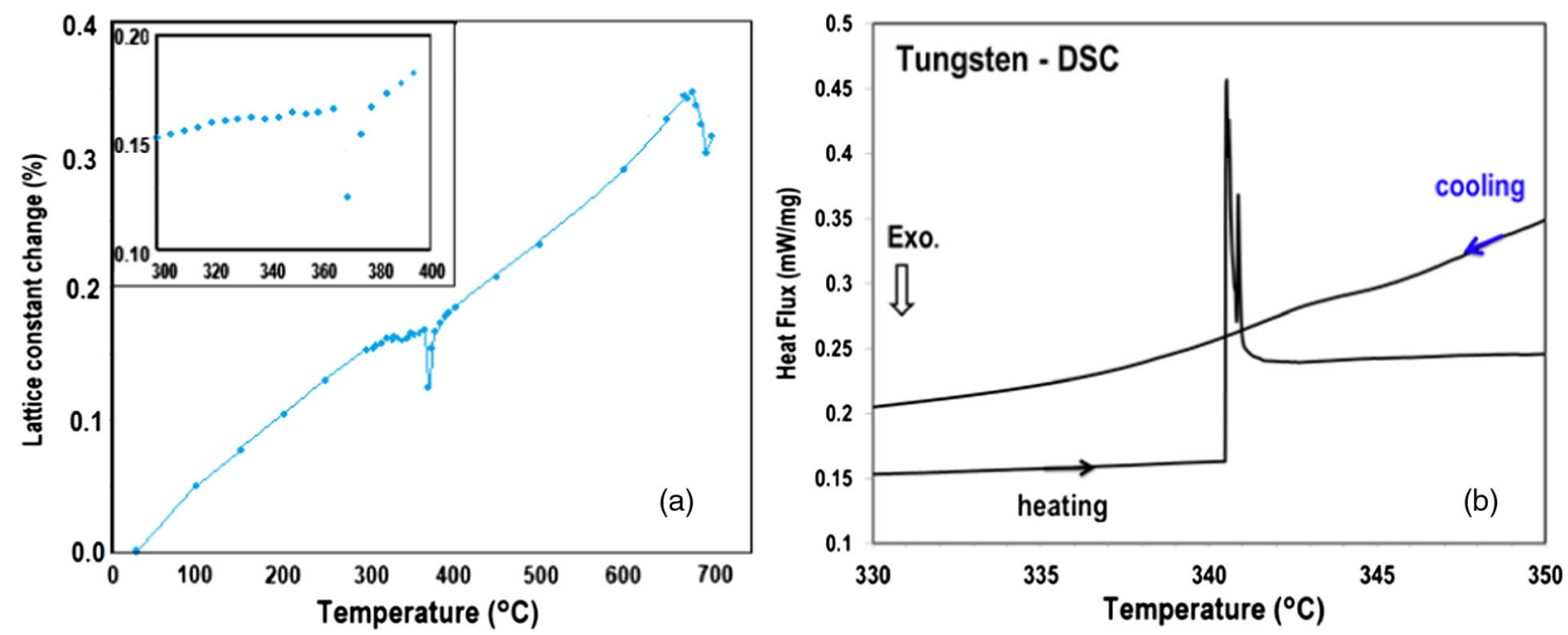

FIG. 25. Temperature dependence of the lattice parameter of unirradiated tungsten (left) and DSC analysis (right) verification of the presence of a "transition" in the vicinity of $\sim 340^{\circ} \mathrm{C}$. 

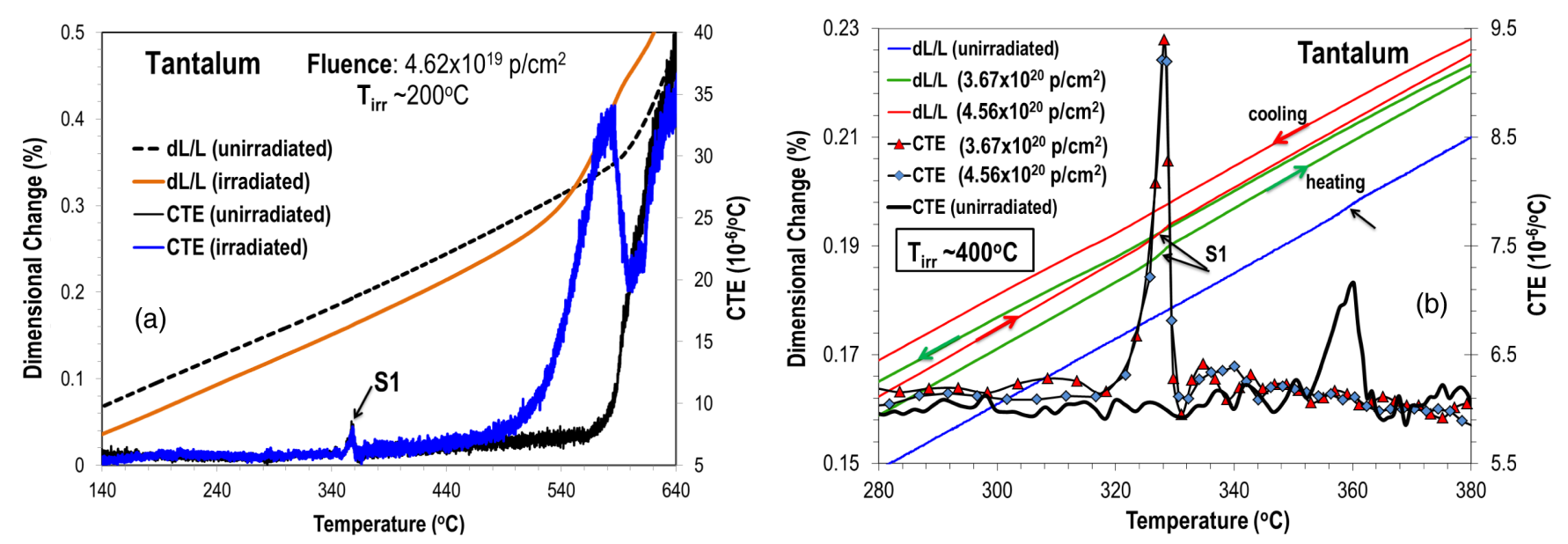

FIG. 26. (a) Proton irradiation effect on the dimensional stability and oxidation of tantalum irradiated at $200^{\circ} \mathrm{C}$, and (b) dimensional change and CTE of tantalum as a function of proton fluence.

grain boundaries. The stress-strain behavior and hardening of proton-irradiated tantalum is shown in Fig. 27(b). Comparison with the unirradiated tantalum a marked irradiation-induced hardening accompanied with reduced ductility, in agreement with the behavior of the material under fast neutron irradiation [27] is observed.

Observed during tensile testing of irradiated tungsten was the type of fracture depicted in Fig. 28 where the head of the tensile specimen fractured as a result of the stress shock waves induced by the extremely high rate of elastic stress release during fracture within the gauge. Numerical shock studies [29] shown in Fig. 28(c) confirmed the fracture characteristics of Fig. 28(b) attributed to the proton-induced elimination of any ductility in the tested tungsten. X-ray diffraction experiments revealing the phase composition and their evolution were conducted and the results, which provide a good explanation of the fracture of
Fig. 28(b), are shown in Fig. 29. These results indicate that the metastable $\beta$-tungsten (A15 cubic) is present along with the stable bec $\alpha$-tungsten (the two phases coexist at ambient conditions owing to nonequilibrium synthesis or stabilization by impurities). The metastable $\beta$-tungsten is rendering some ductility to tungsten due to the larger number of lattice slip planes that it possesses. However, as Fig. 29 shows, the $\beta$-tungsten phase has vanished following irradiation. In the absence of radiation, metastable $\beta$-tungsten converts to $\alpha$-tungsten at $T>600^{\circ} \mathrm{C}$ while the fcc $\gamma$ tungsten converts to $\alpha$-tungsten at $T>700{ }^{\circ} \mathrm{C}$ (traces of the fcc $\gamma$-tungsten are present in the phase map). The lattice parameter for $\alpha-\mathrm{W}$ is reported as $3.16524 \AA$ and for $\beta$-W $5.0512 \AA$. This study revealed lattice parameters of $3.1615 \AA$ (unirradiated $\alpha-\mathrm{W}$ ) and $3.1416 \AA$ (irradiated) and for $\beta$-tungsten $5.0227 \AA$ (unirradiated) and $4.9935 \AA$ (irradiated).
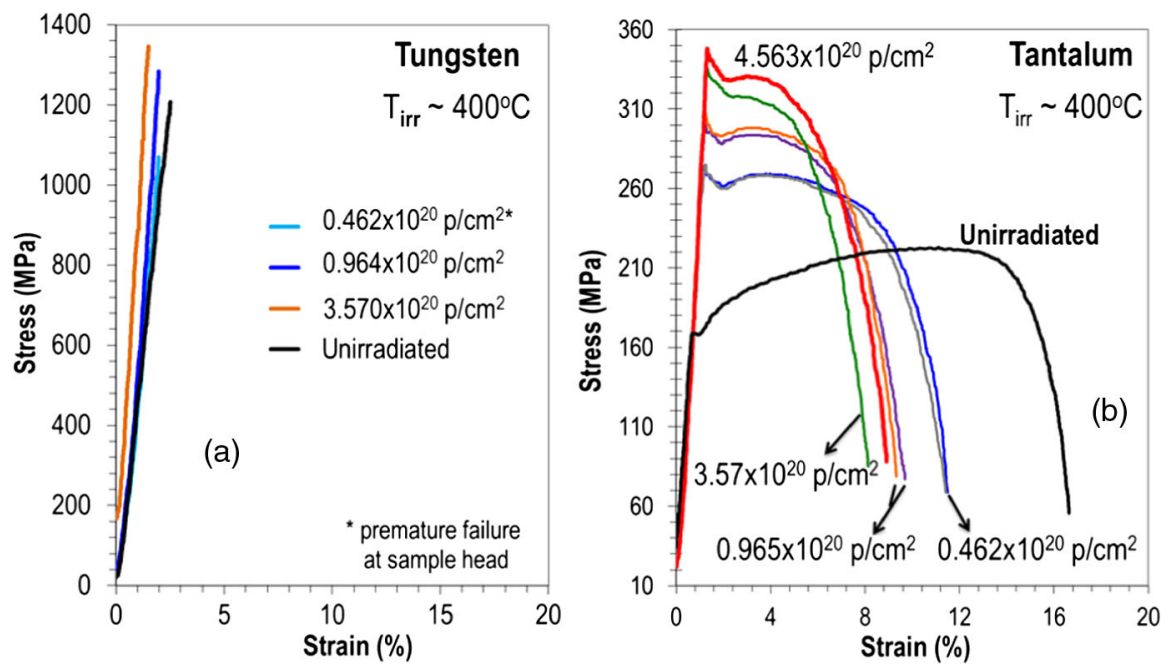

FIG. 27. Proton irradiation effects on stress-strain behavior of (a) tungsten and (b) tantalum. 

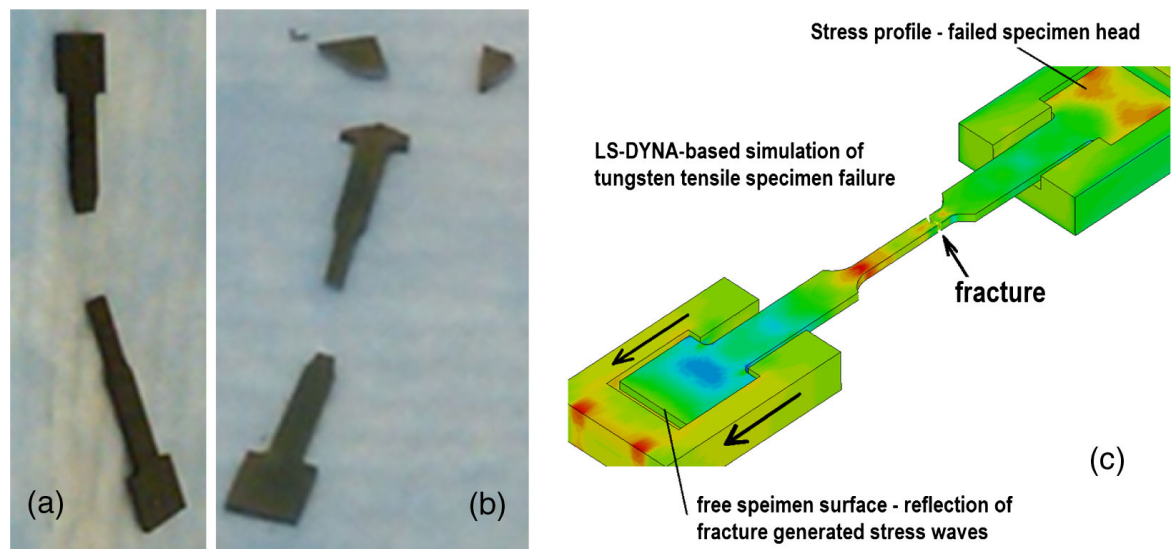

FIG. 28. Tensile test fracture of tungsten (a) unirradiated, (b) irradiated and (c) simulated.
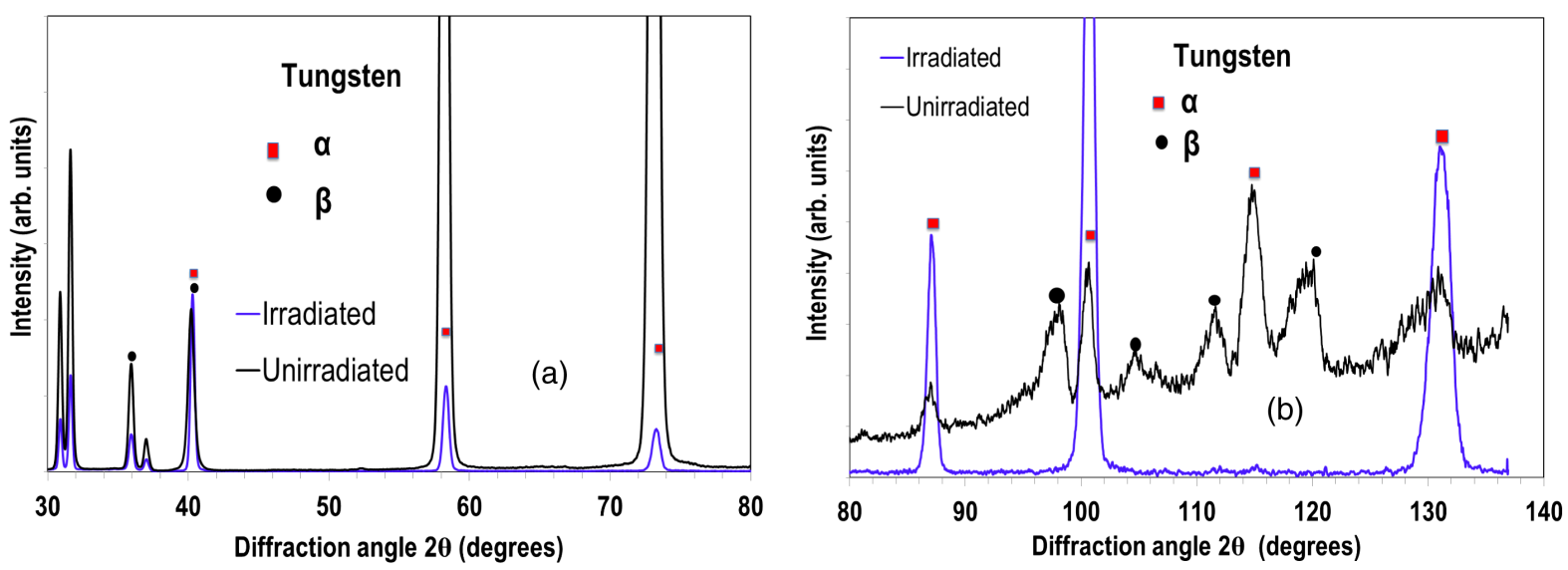

FIG. 29. Irradiation-induced evolution of $\alpha$ and $\beta$ phases in tungsten. (a) 30-80 diffraction angle degree range and (b) 80-140 degree range.

\section{SUMMARY}

To support the needs of several high-power accelerator initiatives in identifying materials and alloys across the atomic-number range as targets that will produce the desired secondary particle spectra, a multiyear study has been undertaken. The study relied on the unique capabilities of proton and synchrotron light source accelerators at Brookhaven National Laboratory for the irradiation and post-irradiation evaluation phases respectively. Specifically, the BNL $200 \mathrm{MeV}$ proton linac was used for the irradiation phase followed by microscopic damage assessment at the NSLS and NSLS II synchrotrons. The microscopic PIE was augmented by macroscopic post-irradiation damage studies at Isotope Processing Facility hot cells where ductility loss and changes in CTE and dimensional stability were assessed. Evolution of the microstructure with temperature but without the effect of radiation was studied at the BNL Center for Functional Nanomaterials.

Presented in this paper are excerpt results of the multifaceted study on selected materials or alloys representing the low-, mid- and high- $\mathrm{Z}$ ranges. These include beryllium, AlBeMet, graphite for the low-Z range, superInvar, Ti-6Al-4V and "gum metal" for the mid-Z and finally tantalum and tungsten for the high- $Z$ regime. The study made a serious attempt to connect macroscopic material behavior following irradiation damage with irradiation effects on the microstructure of the materials and has revealed the following:

The low-Z beryllium and AlBeMet remain dimensionally stable to fluences up to $\sim 10^{20} \mathrm{p} / \mathrm{cm}^{2}$ and exhibit good resistance against ductility loss. The AlBeMet alternative to beryllium is shown to be a composite, not an alloy, in both the unirradiated and irradiated state. Graphite exhibited the ability of removing most of the irradiation damage with post-irradiation annealing to temperatures up to $300^{\circ} \mathrm{C}$ while its CTE increases with dose up to a fluence of $\sim 5 \times 10^{20} \mathrm{p} / \mathrm{cm}^{2}$ beyond which it levels off and begins decreasing. At higher fluences $\left(\sim 8 \times 10^{20} \mathrm{p} / \mathrm{cm}^{2}\right.$ and $T_{\text {irr }} \sim 80^{\circ} \mathrm{C}$ in this study) the microstructure of graphite becomes turbostratic as shown by the disappearance of the (002) crystallographic reflection leading to the loss of structural integrity. 
The study of proton irradiation on the superalloys of the mid-Z range (super-Invar, "gum" metal and Ti-6Al-4V) revealed the following important findings: (a) super-Invar, while it loses the "invar" effect (i.e. low CTE in the range of $0-150^{\circ} \mathrm{C}$ ) upon irradiation, exhibits a full restoration of the effect upon post-irradiation thermal annealing to $\sim 600^{\circ} \mathrm{C}$, undergoes hardening but still maintains a large portion of its ductility and its microstructure is characterized by the presence of two (2) distinct fcc phases along with the bcc phase. (b) The gum metal while in its unirradiated state possesses physiomechanical properties extremely useful for high power targets (high strength, superelasticity, low CTE over a wider temperature range than superInvar), undergoes extreme changes following irradiation. Specifically, modest dose levels $\left(\sim 10^{20} \mathrm{p} / \mathrm{cm}^{2}\right)$ remove the superductility and fully embrittle the material while annealing at temperatures above the transition temperature $\left(\sim 450^{\circ} \mathrm{C}\right)$ cause the "invar-effect" to be permanently eliminated. (c) The Ti-6Al-4V shows good dimensional stability and irradiation-induced hardening similar to that following exposure to fast neutrons for the same dose.

The study on the refractory metals (high Z) tungsten and tantalum used in spallation targets confirmed the serious erosion experienced by tungsten irradiated in water and the insensitivity of tantalum to the same effect. An antiferromagnetic transition in the temperature range of $300{ }^{\circ} \mathrm{C}-400{ }^{\circ} \mathrm{C}$ was confirmed for both tungsten and tantalum. Irradiation-induced hardening of tantalum, similar to that observed under neutron irradiation, was observed for protons. The study has revealed that tungsten, which is brittle at room temperature, exhibits an even more abrupt fracture during post-irradiation tensile testing, an effect attributed to the disappearance of the beta phase of its microstructure induced by irradiation.

\section{ACKNOWLEDGMENTS}

This research used resources at XPD beam line of the National Synchrotron Light Source II, a U.S. Department of Energy (DOE) Office of Science User Facility operated for the DOE Office of Science by Brookhaven National Laboratory under Contract No. DE-SC-0012704. This research used resources at X17-B1 beam line of the National Synchrotron Light Source, a U.S. Department of Energy (DOE) Office of Science User Facility operated for the DOE Office of Science by Brookhaven National Laboratory under Contract No. DE-AC02-98CH10886. The contribution of Dr. Ofan Avishai is acknowledged and appreciated. The most valuable contribution of the late Dr. Hans Ludewig of BNL, is acknowledged.

[1] V. P. Chakin, A. O. Posevin, A. V. Obukhov, and P. P. Lilantyev, Radiation growth of beryllium, J. Nucl. Mater. 386, 206 (2009).
[2] A. Leenaers, G. Verpoucke, A. Pellettieri, L. Sannen, and S. Van den Berghe, Microstructure of long-term annealed highly irradiated beryllium, J. Nucl. Mater. 372, 256 (2008).

[3] V.P. Chakin, V. A. Kazakov, R. R. Melder, Y. D. Goncharenko, and I. B. Kupriyanov, Effects of neutron irradiation at $70^{\circ} \mathrm{C}-200^{\circ} \mathrm{C}$ in beryllium., J. Nucl. Mater. 307, 647 (2002).

[4] S. H. Kang, J. Jang, Y. H. Jeong, and T. K. Kim, Microstructure evolution of beryllium during proton irradiation, J. Korean Phys. Soc. 63, 1414 (2013).

[5] N. Simos, M. Elbakhshwan, Z. Zhong, and F. Camino, Proton irradiation effects on beryllium-A macroscopic assessment, J. Nucl. Mater. 479, 489 (2016).

[6] N. Simos, M. Elbakhshwan, Z. Zhong, S. Ghose, and I. Savkliyildiz, High-temperature annealing of proton irradiated beryllium-A dilatometry-based study, J. Nucl. Mater. 477, 1 (2016).

[7] B.-S. Park and Y.-S. Cho, Mechanical properties of the external beam window for the PEFP, J. Korean Phys. Soc. 54, 1961 (2009).

[8] N. Simos, M. Elbakhshwan, K. T. McDonald, S. Ghose, and Z. Zhong, X-ray diffraction studies of $145 \mathrm{MeV}$ proton-irradiated AlBeMet 162, J. Nucl. Mater. Energy 8, 8 (2016).

[9] A. Burkholtz, Irradiation damage in graphite, Report prepared at the CEN, EUR 3056.e, 1966.

[10] B. T. Kelly, The behavior of graphite under neutron irradiation, J. Vac. Sci. Technol. A 4, 1171 (1986).

[11] B. T. Kelly, On the amorphization of graphite under neutron irradiation, J. Nucl. Mater. 172, 237 (1990).

[12] N. Maruyama and M. Harayama, Neutron irradiation effect of thermal conductivity and dimensional change of graphite materials, J. Nucl. Mater. 195, 44 (1992).

[13] W. Bollmann, Electron-microscopic observations on radiation damage in graphite, Philos. Mag. 5, 621 (1960).

[14] N. Simos, P. Nocera, Z. Zhong, R. Zwaska, N. Mokhov, J. Misek, K. Ammigan, P. Hurh, and Z. Kotsina, Proton irradiated graphite grades for a long baseline neutrino facility experiment, Phys. Rev. Accel. Beams 20, 071002 (2017).

[15] N. Simos et al., Radiation damage and thermal shock response of carbon-fiber-reinforced materials to intense high-energy proton beams, Phys. Rev. Accel. Beams 19, 111002 (2016).

[16] N. Simos, H. G. Kirk, P. Thieberger, H. Ludewig, J. O. Conor, L. Mausner, P.-T. Trung, K. T. McDonald, K. Yoshimura, and J. R. J. Bennett, Irradiation damage studies of high power accelerator materials, J. Nucl. Mater. 377, 41 (2008).

[17] N. Simos, H. Kirk, H. Ludewig, P. Thieberger, W.-T. Weng, K. McDonald, J. Sheppard, G. Evangelakis, and K. Yoshimura, Target material irradiation studies for highintensity accelerator beams, Nucl. Phys. B, Proc. Suppl. 149, 259 (2005).

[18] N. Simos, H. Kirk, H. Ludewig, P. Thieberger, W.-T. Weng, P. T. Trung, K. McDonald, J. Sheppard, K. Yoshimura, and Y. Hayato, Solid target studies for muon colliders and neutrino beams, Nucl. Phys. B, Proc. Suppl. 155, 288 (2006).

[19] T. Saito et al., Multifunctional alloys obtained via a dislocation-free plastic deformation mechanism, Science 300, 464 (2003). 
[20] T. Furuta, S. Kuramoto, J. Hwang, K. Nishino, and T. Saito, Elastic deformation behavior of multifunctional TiNb-Ta-Zr-O alloys, Mater. Trans., JIM 46, 3001 (2005).

[21] Y. Wang, J. Gao, H. Wu, S. Yang, X. Ding, D. Wang, X. Ren, Y. Wang, X. Song, and J. Gao, Strain glass transition in a multifunctional $\beta$-type Ti alloy, Sci. Rep. 4, 3995 (2015).

[22] S. Tahtinen, P. Moilanen, B. N. Singh, and D. J. Edwards, Tensile and fracture toughness properties of unirradiated and neutron irradiated titanium alloys, J. Nucl. Mater. 307, 416 (2002).

[23] V. Tuninetti, G. Gilles, O. Milis, T. Pardoen, and A. M. Habraken, Anisotropy and tension-Compression asymmetry modeling of the room temperature plastic response of Ti-6Al-4V, Int. J. Plast. 67, 53 (2015).

[24] A. Durra Gupta, P. Mukherjee, N. Gayathri, P. Bhattacharyya, M. Bhattacharya, A. Sarkar, S. Sen, and M. K. Mitra, Proton irradiation studies on pure Ti and Ti-6Al-4V, Nucl. Instrum. Methods Phys. Res., Sect. B 387, 63 (2016).

[25] M. Bogomilov et al., Neutrino Factory, Phys. Rev. Accel. Beams 17, 121002 (2014).

[26] H. Ludewig, M. Todosow, N. Simos, S. Shapiro, and J. Hastings, Very high flux steady state reactor and accelerator based sources, in Proceedings of the 12th International Conference on Nuclear Engineering, $\mathrm{Nu}$ clear Engineering Division, Arlington, Virginia, Paper No. ICONE12-49442 (2004), pp. 521-533.

[27] H. Ullmaier and F. Carsughi, Radiation damage problems in high power spallation neutron sources, Nucl. Instrum. Methods Phys. Res., Sect. B 101, 406 (1995).

[28] R. Bennett, N. Simos et al., Thermal shock measurements and modeling for solid high-power targets at high temperature, J. Nucl. Mater. 377, 285 (2008).
[29] T. T. Böhlen, F. Cerutti, M. P. W. Chin, A. Fassò, A. Ferrari, P. G. Ortega, A. Mairani, P. R. Sala, G. Smirnov, and V. Vlachoudis, The FLUKA code: Developments, and challenges for high energy, and medical applications, Nucl. Data Sheets 120, 211 (2014).

[30] A. Ferrari, P. R. Sala, A. Fassò, and J. Ranft, FLUKA: A multiparticle transport code, Reports No. CERN2005-10, No. INFN/TC_05/11, and No. SLAC-R-773, 2005.

[31] LS-DYNA, Version 9.71, Livermore Software Technology Corp. (LSTC), 2007.

[32] Yu. M. Smirnov and V. A. Finkel, Crystal structure of tantalum, niobium and vanadium at 110-400 K, Sov. Phys. JETP 22, 750 (1966).

[33] R. J. Talling, R. J. Dashwood, M. Jackson, and D. Dye, On the mechanism of superelasticity in gum metal, Acta Mater. 57, 1188 (2009).

[34] S. Makimura et al., Design of muon target at JPARC, in Proceedings of the 14th Symposium on Accelerator Science and Technology, Tsukuba, Japan, 2003 (2003), p. 22.

[35] R. S. Lillard, D. L. Pile, and D. P. Butt, The corrosion of materials in water irradiated by $800 \mathrm{MeV}$ protons, J. Nucl. Mater. 278, 277 (2000).

[36] S. Sawada, Thermal and electrical properties of tungsten oxide $\left(\mathrm{WO}_{3}\right)$, J. Phys. Soc. Jpn. 11, 1237 (1956).

[37] J. Stinger, Oxidation of tantalum in oxygen-nitrogen and oxygen-inert gas mixtures, Oxid. Met. 11, 225 (1977).

[38] N. Simos et al., Transitions in $\mathrm{WO}_{3}$ and the influence of irradiation (unpublished). 